\title{
Dynamic panel data estimation of an integrated Grossman and Becker-Murphy model of health and addiction
}

\author{
Andrew M. Jones ${ }^{a, *} \quad$ Audrey Laporte ${ }^{b, c} \quad$ Nigel Rice ${ }^{a, d}$ \\ Eugenio Zucchelli ${ }^{e}$ \\ ${ }^{a}$ Department of Economics and Related Studies, University of York, YO10 5DD, UK \\ ${ }^{b}$ Institute for Health Policy, Management and Evaluation, University of Toronto, ON \\ M5T 3MS, Canada \\ ${ }^{c}$ Canadian Centre for Health Economics, University of Toronto, Canada \\ ${ }^{d}$ Centre for Health Economics, University of York, YO10 5DD, UK \\ e Division of Health Research, Lancaster University, LA1 4YG, UK
}

October 30, 2017

\begin{abstract}
We propose a dynamic panel data approach to estimate a model that integrates the Becker-Murphy theory of rational addiction with the Grossman model of health investment. We define an individual's lifetime smoking consumption and investments in health capital as simultaneous choices within a single optimisation problem. We show that this can be estimated using GMM system estimation of two stand-alone single fourth-order difference equations of health capital and smoking. These preserve roots and fundamental dynamics of the original system of four interrelated first-order equations. Monte Carlo simulations confirm that this reduced-form dynamic estimation also produces very similar estimates to the ones of the initial system of equations. We argue that, in the presence of long panel data, this approach may provide a feasible alternative for the estimation of a complex life-cycle model of human capital.
\end{abstract}

JEL classification: C1, C3, C5, C6, I1.

Key words: Addiction; Health capital; Smoking; Dynamic panel data models

\section{Acknowledgements}

The authors gratefully acknowledge funding from the Economic and Social Research Council (ESRC) under grant reference RES-060-25-0045. We are grateful to Victor Aguirregabiria, Jonneke Bohlaar, Brenda Gannon, Eleonora Fichera, Aloysius Siow, Matt Sutton, and participants of the 8th International Health Economics Association (iHEA) Congress in Toronto, the 9th European Conference on Health Economics (ECHE) in Zurich, the 2012 Applied Health Econometrics Symposium 
at the University of Leeds, the 2012 Netspar Conference on Health and Inequality in the Life-cycle in Rotterdam as well as participants of seminars at Universities of Barcelona, Leeds, Newcastle, Toronto and York for discussions and helpful comments. Data from the British Household Panel Survey were supplied by the Economic and Social Research Council Data Archive. Neither the original collectors of the data nor the Archive bear any responsibility for the analysis or interpretations presented in this manuscript.

*Corresponding author: Andrew Jones. Tel.: +44 1904323766.

E-mail address: andrew.jones@york.ac.uk 


\section{Introduction}

The dominant theoretical model in the economics of health, broadly speaking, is the Grossman model (?). The model extends the theory of human capital to the demand for health and medical care over the life-cycle and provides the foundation for a large body of empirical research. Similarly, the leading theoretical model in the economic analysis of the consumption of addictive commodities is the Becker-Murphy model of rational addiction (?; henceforth B-M). Although each model is a subset of the general model of investment in human capital (???), up until very recently the two models have been considered as separate entities for both theoretical and empirical analyses (??). In addition, the empirical testing of the Grossman model has often been hampered by data constraints, particularly by the shortage of long panel data required to reflect appropriately its dynamic nature (??).

We develop and estimate a model that explicitly integrates the dynamics of addiction and the human capital model of health investment. This enables the modelling of smoking behaviour and positive investments in health capital as simultaneous choices of a single optimization problem, allowing for the presence of an addiction stock together with a stock of health capital and investments in preventive medical care. We derive a reduced-form that can be estimated using high-order linear dynamic panel data models while preserving the roots of the original system. This integrated model is consistent with insights from both the medical literature on the health effects of smoking (e.g. ?) and the recent developments in the economics literature (e.g. ?). Those studies suggest that smoking has a cumulative effect in the sense that its impact on an individual's health capital depends not on how much is smoked today but on the amount of smoking damage accumulated over their lifetime. Consistent with the B- 
M framework we model smoking damage as a state variable in an optimal control framework allowing it to have its own intrinsic dynamics. Following Grossman we also model health capital as a state variable with its own intrinsic dynamics, but enter the stock of smoking damage as an explanatory variable in the equation explaining health damage. This allows smoking to have its own dynamics but also to have a different time profile of effect on health than other health related activities.

The resulting inter-temporal optimisation leads to a system of interrelated first-order difference equations. Empirical implementation of this system is complicated by the fact, not uncommon in health datasets, that we lack data on certain key choice variables - most obviously on levels of addiction. We therefore reduce the system from four inter-related first-order difference equations to a pair of stand alone fourth-order difference equations, one in health and one in cigarette consumption. This derivation allows the roots of each of the single fourth-order difference equations to be the same as the four roots of the original system of four first-order difference equations and accordingly can be used to investigate the dynamics of the system. Monte Carlo simulations confirm that this derived reduced-form dynamic estimation approach produces very similar estimates to those of the initial system.

Our approach requires the estimation of dynamic panel data models involving fourth-order lags of the dependent variable. We do this using a generalised method of moments (GMM) systems estimator deriving instruments for the lags of the dependent variable from past period observations. This necessitates the use of rich and mature panel data and we make use of 18 waves of the British Household Panel Survey (BHPS). Our estimates confirm the strong persistence of both smoking consumption and health capital with direct effects on current health and smoking observed for up to three and four lagged pe- 
riods for men and women respectively. The dominant real roots which drive the long-term behaviour of health and smoking consumption are both positive and less than one in absolute value, and are numerically similar across the equations and generally also for men and women. Conditional on the intrinsic dynamics in the health and smoking equations, we also find a limited role for socio-economic status.

Our paper offers several contributions to the literature. First, we build on recent advancements and propose a model that treats the theories of Grossman and B-M as complementary and integrates these into a single framework. Secondly, we show how this integrated model can be estimated empirically using dynamic panel data models for both health and smoking. Thirdly, we employ Monte Carlo simulations to illustrate the validity of our reduction strategy. We argue that the approach provides a feasible alternative for the estimation of a complex life-cycle model of human capital.

The paper is organised as follows. Section ?? provides a background to the rational addiction model and the Grossman model of health capital investment and maps out the way in which these theories can be integrated. Section ?? presents our theoretical approach that nests the Grossman model within the B-M framework. Sections ?? and ?? present our empirical approach and data respectively. Results follow in section ?? and section ?? presents a discussion of the findings.

\section{Background}

Early applications of the rational addiction model were focused on the analysis of cigarette consumption based on aggregate level data (??). In this framework, rationality involves forward-looking behaviour or a plan to maximise 
utility over time and, accordingly, individuals anticipate the future (harmful) consequences of their current choices. These studies appear to broadly support the main implications of rational addictive behaviour, and reject myopic behaviour.1 In standard B-M models addiction is often considered the only factor that affects an individual's health while health capital and its evolution over the life-cycle are not explicitly modelled.

More recent applications on tobacco consumption employ dynamic panel data specifications and focus on issues such as errors-in-variables, data censoring and individual-level unobserved heterogeneity (e.g. ??). In general, these models also reject myopic behaviour and support B-M. The dynamic framework of addiction has also been applied to the analysis of consumption of other addictive goods such as alcohol (????) and illicit drugs such as cocaine, heroin and marijuana (e.g. ??) $!^{2}$

The seminal work of Grossman (?) draws from the literature on human capital theory (???) and applies it to the demand for health and medical care over the life-cycle. In this framework, individuals inherit an initial health capital stock that, while depreciating with age, can be increased through investments in health (for example, via medical care). Extensions to the model tend to focus on its underlying assumptions and implications concerning optimal investments (e.g. ?), specific aspects of labour supply (such as illness-related work absence as in ?) and education (?).

There are few economic studies that model aspects of health and smoking jointly. ? estimate a recursive system of equations for lifestyles, morbidity

\footnotetext{
${ }^{1}$ Note, however, that most studies are not conclusive in this respect and often produce implausible estimates of discount rates. However, see ? for a discussion of potential dynamic inconsistencies in preferences with respect to smoking. Note that our paper is concerned with embedding the Grossman model within the B-M framework and is not explicitly concerned with estimating discount rates.

${ }^{2}$ Baltagi and other authors have also extensively explored the application of panel data methods on both tobacco and alcohol consumption, e.g. ???.
} 
and mortality and explore health inequalities in mortality using decomposition techniques on data from the British Health and Lifestyle Survey. They find that lifestyles appear to contribute strongly to inequality in mortality, reducing the direct role of socio-economic status. ? proposes a B-M model of smoking augmented by a Bayesian learning process through which individuals acquire information about their own health and use it to make decisions about smoking. ? employ hazard models on data drawn from the Swedish Survey of Living Conditions merged with death records to analyse the effect of smoking on mortality. They find evidence of selection into smoking such that individuals with poorer health are more likely to smoke and that the effect of smoking on mortality appears to be larger for individuals with a potentially longer life expectancy as measured by a series of proxies for health status. More recently, ? build a dynamic model of health, wealth and education that also allows individuals to make rational forward-looking decisions on (generic) unhealthy behaviours. Overall, these studies have focused on specific aspects of the interactions between health (longevity and individual health information), education and lifestyles but do not attempt to formally set out a model of the dynamic interrelations between smoking and health capital.

\section{Theoretical model}

\subsection{The standard model of rational addiction}

The B-M model analyses smoking choices in an inter-temporal optimization framework where the quantity of cigarettes smoked is the control variable and the stock of addiction capital is the state variable. In discrete time terms, the 
elements of the standard B-M model can be written as ${ }^{3}$

$$
\max \sum_{t=0}^{\infty} \beta^{t} U\left(C_{t}, S_{t}, A_{t}\right),
$$

with $U_{C}>0, U_{C C} \leq 0 ; U_{S}>0, U_{S S} \leq 0 ; U_{A}<0, U_{A A} \leq 0 ; U_{S A}>0$;

$$
A_{t}=f\left(S_{t}\right)+\left(1-\delta_{A}\right) A_{t-1}, \quad f_{S}>0, f_{S S} \leq 0
$$

$$
Y_{t}=C_{t}+p_{S} S_{t}
$$

where $S_{t}$ is the quantity of cigarettes consumed in period $t, A_{t}$ is the stock of addiction, $C_{t}$ refers to other commodities and $Y_{t}$ is income. The relative price of $S$ is $p_{S}$ with the price of $C$ normalized to $1 ; \delta_{A}$ is the rate at which the stock of addiction decays and $\beta$ is the discount factor. The marginal utilities of $C_{t}$ and $S_{t}$ are positive and decreasing while that of $A_{t}$ is negative and decreasing. The intertemporal utility function (??) is maximized by choice of $C_{t}$ and $S_{t}$. 4 The equation of motion for the addiction stock is given by (??). Here smoking is assumed to have a positive effect on $A_{t}$, although due to the difficulty in measuring $A_{t}$, it is usually assumed that $f\left(S_{t}\right)$ is linear for $A_{t} !^{5}$ This problem is solved as an optimal control problem, yielding necessary conditions which include the equation of motion of $A_{t}$, a terminal transversality condition and an Euler equation for $S_{t}$. The resulting first-order difference equation in $S_{t}$ interacts with the first-order difference equation for $A_{t}$. This is a straightforward optimal control problem, which could be analysed qualitatively

\footnotetext{
${ }^{3} \mathrm{~B}-\mathrm{M}$ models often include a wealth equation (e.g. ?). This is omitted here as it is not essential to our narrative.

${ }^{4}$ In this version of the model, where borrowing is not permitted, $C_{t}$ and $S_{t}$ are tied together by the budget constraint (??) which allows us to substitute $C_{t}$ out of the problem.

${ }^{5}$ This assumption of linearity does not impact on the qualitative solution to the problem.
} 
using a phase diagram in $S_{t}$ and $A_{t}$.

A standard problem in the empirical literature is the difficulty of measuring $A_{t} \bigsqcup^{6}$ In the majority of applications this is handled by the reduction of the system of two first-order difference equations, one in $S_{t}$ and one in $A_{t}$, to a single second-order difference equation in $S_{t}$, where $S_{t}$ (consumption of cigarettes) is the observable variable (see ?). This reduction is standard in the dynamics literature (see ?), and preserves the characteristic roots of the system, which drive the dynamics of both $A_{t}$ and $S_{t}$. In what follows we will employ a similar strategy and reduce a system of four first-order difference equations resulting from optimization into two fourth-order difference equations; one in health and one in smoking, while preserving the characteristic roots of the initial system.

\subsection{Integrating the Grossman model}

A limitation of the standard B-M model is that the only factor which represents or affects an individual's health is the stock of addiction capital, $A_{t}$. We augment the model with a Grossman model of investment in health capital, where the investment goods include harmful health 'bads' (cigarette consumption) as well as the usual investment 'goods'. To extend the B-M model to include the demand for health, we write the individual's lifetime utility function as:

$$
\sum_{t=0}^{\infty} \beta^{t} U\left(C_{t}, S_{t}, H_{t}, A_{t}\right),
$$

with $U_{C}>0, U_{C C}<0 ; U_{S}>0, U_{S S}<0 ; U_{A}<0, U_{A A}<0 ; U_{S A}>0 ; U_{H}>$ $0, U_{H H}<0 . H_{t}$, is the stock of health capital at time $t$. Addiction capital, $A_{t}$, remains as an argument in the utility function since an individual derives disutility from being addicted, even though the health effects of smoking, which

\footnotetext{
${ }^{6}$ Some studies have used biological markers which are used to reflect the addictive stock $(? ?)$
} 
rises with the cumulative amount smoked over time, could be absorbed into $H_{t} . H_{t}$ cannot be purchased directly, but rather must be produced using an input $M_{t}$, which can be purchased. Accordingly, the budget constraint is now:

$$
Y_{t}=C_{t}+p_{S} S_{t}+p_{M} M_{t}
$$

where the price of cigarettes, $p_{S}$, and medical care, $p_{M}$, are relative to the price of other consumption goods, $C$. We retain the equation of motion for $A$, given by (??), and specify the following equation of motion for $H$ :

$$
H_{t+1}=\left[1-\delta_{H}\right] H_{t}+h\left(M_{t}\right)+l\left(A_{t}\right), \quad h_{M}>0, h_{M M}<0 ; l_{A}<0, l_{A A} \leq 0 .
$$

$A_{t}$ appears in the equation of motion for $H$ to represent the cumulative effects of smoking on cumulated health capital. Even if an individual quits smoking, such that $S=0$, the accumulated addiction stock will continue to harm their health (reduce health capital) until it has decayed away. We assume that investing in health via the purchase of medical care, $M_{t}$, does not produce utility per se 7 After substituting $C$ out of the utility function, using the budget constraint, the problem, written in Chow's Lagrange multiplier format (see ?) is:

$$
\begin{array}{r}
\operatorname{Max} \sum_{t=0}^{\infty} \beta^{t} U\left(Y_{t}-p_{S} S_{t}-p_{M} M_{t}, S_{t}, A_{t}, H_{t}\right)-\beta^{t+1} \lambda_{t+1}\left[H_{t+1}-\left[1-\delta_{H}\right] H_{t}\right. \\
\left.-h\left(M_{t}\right)-l\left(A_{t}\right)\right]-\beta^{t+1} \mu_{t+1}\left[A_{t+1}-\left[1-\delta_{A}\right] A_{t}-f\left(S_{t}\right)\right],
\end{array}
$$

\footnotetext{
${ }^{7}$ More generally $M$ can represent any good which is beneficial for health but yields no direct utility. We follow the standard approach in the literature and denote this as medical care.
} 
where $\lambda$ and $\mu$ represent the shadow price of health and addiction capital respectively. Since addiction is a 'bad', $\mu$ is negative while $\lambda$ is positive because health capital is a 'good'.

The corresponding first-order conditions are

$$
\begin{gathered}
\beta \mu_{t+1}=p_{S} U_{C}(t)-U_{S}(t), \\
\beta \lambda_{t+1} h\left(M_{t}\right)=p_{M} U_{C}(t), \\
\beta\left[1-\delta_{H}\right] \lambda_{t+1}=\lambda_{t}-U_{H}(t), \\
\beta^{t+1}\left[1-\delta_{A}\right] \mu_{t+1}=\mu_{t}-U_{A}(t)-\beta^{t+1} \lambda_{t+1} l\left(A_{t}\right) .
\end{gathered}
$$

The equation of motion for the shadow price of addiction capital (??) now contains the shadow price of health capital, $\lambda$, reflecting the fact that the stock of addiction capital is a determinant of the stock of health capital. The firstorder conditions can be rearranged to eliminate the Lagrange multipliers. In so doing, we assume that these conditions always hold, meaning that individuals are in fact optimizing. Rearranging yields the following system of four firstorder nonlinear difference equations in $M_{t}, S_{t}, A_{t}$ and $H_{t}$ :

$$
\left[1-\delta_{H}\right] \frac{\left(p_{M} U_{C}(t)\right)}{h\left(M_{t}\right)}=\frac{p_{M} U_{C}(t-1)}{\beta h\left(M_{t-1}\right)}-U_{H}\left(H_{t}\right)
$$

${ }^{8}$ The arguments of utility, for example, $U_{C}(t)$, denote the time period to which utility refers. 


$$
\begin{gathered}
{\left[1-\delta_{A}\right] p_{S} U_{C}(t)-\left[1-\delta_{A}\right] U_{S}(t)=p_{S} U_{C}(t-1)-\frac{U_{S}(t-1)}{\beta}} \\
-U_{A}(t)-\frac{p_{M} U_{c}(t)}{h\left(M_{t}\right) l\left(A_{t}\right)}, \\
A_{t+1}=\left[1-\delta_{A}\right] A_{t}+f\left(S_{t}\right), \\
H_{t+1}=\left[1-\delta_{H}\right] H_{t}+h\left(M_{t}\right)+l\left(A_{t}\right) .
\end{gathered}
$$

This system of first-order difference equations can be expressed as four linearized first-order difference equations in $H_{t}, S_{t}, A_{t}$ and $M_{t}$ which, in turn, can be reduced into a single fourth-order equation in $S_{t}$ or $H_{t}$. These form the basis of our empirical model.

\section{Empirical models}

\subsection{Derivation of estimating equations}

The starting point for our estimation strategy follows the original B-M model as described by equations (??) to (??). The first-order conditions for this model can be rearranged as a pair of first-order difference equations in $S_{t}$ and $A_{t}$. However, the B-M model is typically estimated as the following linear second-order difference equation in $S$ :

$$
S_{t}=\alpha_{0}+\alpha_{1} S_{t+1}+\alpha_{2} S_{t-1}+\epsilon_{t}
$$

Typically this is referred to as a forward looking second-order difference equation, since it contains $S_{t+1}$ on the right-hand side and it is often said that the forward looking nature of this equation reflects the rationality of 
the consumption decision. In fact, rationality is a consequence of this equation having emerged from an inter-temporal optimization problem and is in many ways inherent in the first-order condition (??) which we can rewrite as: $-\beta \mu_{t+1}=U_{S}(t)-p_{S} U_{C}(t)$. In this expression, $\mu_{t+1}$ is the shadow price of another unit of addiction capital (negative since addiction capital yields disutility). The right-hand side of this expression is the net benefit in utility terms that the consumer derives from consuming another unit of $S_{t}$ net of the utility given up because consuming more $S$ requires consuming less $C$. The fact that the benefit is derived in period $t$ and the cost in $t+1$ is the essence of the forward looking nature of the decision.

The standard empirical specification of the B-M model (??) is written with one lead and one lag of the dependent variable on the right-hand side. This specification, is however, not necessary and could be rearranged and written with two lags on the right-hand side. The process of reducing the two interrelated first-order difference equations which fall out of the necessary conditions of the usual version of the B-M model to a single second-order difference equation does not affect the fact that the necessary conditions are forward looking, regardless of how we happen to write the second-order equation.

Our estimation strategy set out below is based on an extension of the standard B-M approach, where we reduce our set of four interrelated firstorder difference equations (??) to a single fourth-order difference equation. For tractability, we follow a practice which is common in the literature on analytical dynamics, when expressions for characteristic roots are being found for a model which is intrinsically nonlinear, and assume that we are working with a linear

\footnotetext{
${ }^{9}$ This is because the B-M problem is, as noted above, an inter-temporal optimization problem which is typically set up as an optimal control problem. The solution equations to an optimal control problem are necessary conditions for optimizing the present value of the stream of future utilities which will arise from future consumption decisions, taking account of how current consumption affects future addiction.
} 
approximation to the original non-linear system. These assumptions about functional form lead to four linearised first-order difference equations which can be reduced further into single fourth-order linear equations for estimation (see Appendix A for an illustration of how the reduction procedure works). We do this separately for smoking and health which yields the following general forms:

$$
\begin{aligned}
& S_{i t}=\phi_{s 0}+\phi_{s 1} S_{i t-1}+\phi_{s 2} S_{i t-2}+\phi_{s 3} S_{i t-3}+\phi_{s 4} S_{i t-4}+\theta_{s 1} X_{i t}^{s}+\theta_{s 2} X_{i t-1}^{s} \\
& +\theta_{s 3} X_{i t-2}^{s}+\theta_{s 4} X_{i t-3}^{s}+\psi_{s} W_{i}^{s}+\mu_{i s}+\left(\epsilon_{i t}+\rho_{\epsilon 1} \epsilon_{i t-1}+\rho_{\epsilon 2} \epsilon_{i t-2}+\rho_{\epsilon 3} \epsilon_{i t-3}\right)
\end{aligned}
$$

$$
\begin{aligned}
& H_{i t}=\phi_{h 0}+\phi_{h 1} H_{i t-1}+\phi_{h 2} H_{i t-2}+\phi_{h 3} H_{i t-3}+\phi_{h 4} H_{i t-4}+\theta_{h 1} X_{i t}^{h}+\theta_{h 2} X_{i t-1}^{h} \\
& +\theta_{h 3} X_{i t-2}^{h}+\theta_{h 4} X_{i t-3}^{h}+\psi_{h} W_{i}^{h}+\mu_{i h}+\left(\varepsilon_{i t}+\rho_{\epsilon 1} \varepsilon_{i t-1}+\rho_{\epsilon 2} \varepsilon_{i t-2}+\rho_{\epsilon 3} \varepsilon_{i t-3}\right) \\
& \quad \text { for } i=1, \ldots, N \text {, and } t=1, \ldots, T .
\end{aligned}
$$

Here $S_{i t}$ represents smoking consumption for individual $i$ at time $t ; H_{i t}$ is the stock of health; $X_{i t}^{s}$ and $X_{i t}^{h}$ are sets of exogenous time-varying predictors of smoking consumption and health respectively. $W_{i}^{s}$ and $W_{i}^{h}$, and $\mu_{i s}$ and $\mu_{i h}$ are respectively time-invariant predictors and time-invariant individualspecific unobserved effects for smoking and health 10 We assume that $\epsilon_{i t} \sim$ i.i.d. $\left(0, \sigma_{\epsilon}^{2}\right)$ with $E\left(\epsilon_{i t}\right)=0$ and, similarly, $\varepsilon_{i t} \sim$ i.i.d. $\left(0, \sigma_{\varepsilon}^{2}\right)$ with $E\left(\varepsilon_{i t}\right)=0$. Also, we assume that $E\left(X_{i r}^{s}, \epsilon_{i t}\right)=0, E\left(X_{i r}^{h}, \varepsilon_{i t}\right)=0$ for $\forall r, t$. That is, $X^{s}$ and $X^{h}$ include strictly exogenous regressors uncorrelated with $\epsilon$ and $\varepsilon$ respectively. Both sets of time-varying predictors may, however, be correlated with their

\footnotetext{
${ }^{10}$ See the Appendix for an illustration of which exogenous variables from the original system end up in each equation.
} 
respective unobserved effects, $\mu_{i s}$ and $\mu_{i h}$. We assume that the time-invariant regressors $W_{i}^{s}$ and $W_{i}^{h}$ are orthogonal to the unobserved time-varying effects ${ }^{11}$ Note that the equations contain third-order moving average processes in the error $(\mathrm{MA}(3)){ }^{12}$

\subsection{Monte Carlo Simulations}

To illustrate the validity of our reduced-form estimation approach, we implement a series of Monte Carlo (MC) simulations. For tractability and computational ease, we consider a reduction of a simple system of two first-order difference equations into a single second-order difference equation. Parameter estimates across the MC replicates confirm that the reduction process maintains the characteristic roots of the original system. The result readily extends to the four first-order difference equations and the corresponding reduction to single fourth-order equations outlined above.

The system can be written as:

$$
\begin{aligned}
& Y_{1 t}=\phi_{10}+\phi_{11} Y_{1 t-1}+\phi_{12} Y_{2 t-1}+\theta_{11} X_{1 t}+\theta_{12} X_{2 t}+\varepsilon_{1 t} \\
& Y_{2 t}=\phi_{20}+\phi_{21} Y_{1 t-1}+\phi_{22} Y_{2 t-1}+\theta_{21} X_{1 t}+\theta_{22} X_{2 t}+\varepsilon_{2 t}
\end{aligned}
$$

\footnotetext{
${ }^{11}$ It might be argued that this assumption is unrealistic. However, relaxing the assumption requires either the identification of external instruments for $W_{i}$, or relying on instruments internal to the model. The latter might consist of transformations of $X_{i t}, \ldots, X_{i t-3}$ where a subset of these are assumed to be uncorrelated with the unobserved individual specific effect in the spirit of Hausman and Taylor type estimators (?). Alternatively, differences in the lags of the dependent variable can be used as instruments. It is not surprising, however, that such instruments are weak when used in this context. Estimates of the lagged dependent variables, $S_{i t-1}, \ldots, S_{i t-4}$ and $H_{i t-1}, \ldots, H_{i t-4}$ do not change dramatically for models estimated without the vector of time-invariant regressors.

${ }^{12}$ In addition to the MA(3) structure, the error terms will also include cross-error elements. Note also that the equation-specific disturbance terms in (8) and (9) may contain the disturbance terms from the original system of four equations. See the Appendix for an illustration of these issues.
} 


$$
\begin{aligned}
& X_{1 t}=\gamma_{12} X_{1 t-1}+\epsilon_{1 t} \\
& X_{2 t}=\gamma_{22} X_{2 t-1}+\epsilon_{2 t}
\end{aligned}
$$

This is a system of two-interrelated first-order difference equations with a single exogenous variable in each equation, no cross-equation elements in the variance-covariance matrix, and normally distributed error terms. The characteristic roots of the matrix of coefficients in equation (??) are: ${ }^{13}$

$$
\lambda_{1,2}=0.925 \pm 0.198 i
$$

The roots are complex and accordingly the data should display cycles. The modulus of the roots is 0.946 , so the cycles are stable. That is, the $Y$ values will tend to converge to their equilibrium, although the fact that the $X$ variables are themselves driven by stable first order difference equations (with no cross equation terms in the $X^{\prime} s$ ) means that we are in fact dealing with a moving equilibrium.

We run the $\mathrm{MC}$ experiments on the system in time series form to avoid having to deal with issues relating to panel data estimation (given that our focus is the validity of the reduction procedure) ${ }^{14}$ Each replicate contains a

${ }^{13}$ The corresponding matrix of coefficients defining the data-generating process (DGP) for the $\mathrm{MC}$ exercise is:

$$
\begin{gathered}
{\left[\begin{array}{l}
Y_{1 t} \\
Y_{2 t}
\end{array}\right]=\left[\begin{array}{l}
100 \\
300
\end{array}\right]+\left[\begin{array}{cc}
0.9 & -0.4 \\
.10 & .95
\end{array}\right]\left[\begin{array}{l}
Y_{1 t-1} \\
Y_{2 t-1}
\end{array}\right]+\left[\begin{array}{cc}
0.4 & 0 \\
0 & 0.6
\end{array}\right]\left[\begin{array}{l}
X_{1 t} \\
X_{2 t}
\end{array}\right]+\left[\begin{array}{l}
\varepsilon_{1 t} \\
\varepsilon_{2 t}
\end{array}\right]} \\
{\left[\begin{array}{l}
X_{1 t} \\
X_{2 t}
\end{array}\right]=\left[\begin{array}{cc}
0.6 & 0 \\
0 & 0.4
\end{array}\right]\left[\begin{array}{l}
X_{1 t-1} \\
X_{2 t-1}
\end{array}\right]+\left[\begin{array}{l}
\epsilon_{1 t} \\
\epsilon_{2 t}
\end{array}\right]}
\end{gathered}
$$

The matrix multiplying the vector of lagged $Y$ 's contains the $\phi$ 's while the matrix multiplying the vector of $X$ 's includes the $\theta$ 's. For simplicity, we made this matrix of $Y$ 's diagonal such that $\theta_{12}=\theta_{21}=0$.

${ }^{14}$ To run the experiment, we use the MC routine within the PcNaive module of the PcGive econometrics package. For the first equation the initial values for the lagged $Y^{\prime} s$ were 10,000 
sample size of $T=500(N=1)$, and we run $M=1000$ replications. Column (1) of Table ?? provides true parameter values used to simulate the data for the system of equations described in (??) and (??). The table also shows the MC estimated coefficients (means for each estimated parameter over the set of $\mathrm{MC}$ replications) and corresponding standard errors. As can be seen the $\mathrm{MC}$ estimates are very close to the true values under the data generating process. The calculated roots generated from the estimated coefficients from the MC exercise are:

$$
\lambda_{1,2}=0.924 \pm 0.197 i
$$

Note that we are running these MC experiments on the premise that one of the variables, in our case $Y_{2 t}$, is in fact unobservable. The theoretical argument as set out in the paper suggests that we should be able to extract estimates of many of the structural coefficients of the true system from a suitable dynamic reduction, going from a system of two interrelated first-order difference equations to a single second-order difference equation. The single second-order difference equation could be written as follows (note we use ${ }^{\sim}$ to differentiate the parameters to those of equation (??)):

$$
Y_{1 t}=\tilde{\phi}_{10}+\tilde{\phi}_{11} Y_{1 t-1}+\tilde{\phi}_{12} Y_{1 t-2}+\tilde{\theta}_{11} X_{1 t}+\tilde{\theta}_{12} X_{1 t-1}+\tilde{\theta}_{13} X_{2 t-1}+\tilde{\varepsilon}_{1 t}
$$

MC estimation of equation (??) produces estimates reported in column (2)

for Yt-1 and 9,000 for Yt-2. For the second equation the initial values for the lagged $Y^{\prime} s$ were also 10,000 for Yt-1 and 9,000 for Yt-2. The $X^{\prime} s$ were drawn from a normal distribution with mean 0 and variance 100 for both equations. Since we have a dynamically stable and unique equilibrium, regardless of what initial values we chose, the system would converge on that equilibrium. We simply chose these values to be sure we were starting the process a long way away from the equilibrium. 
of Table ??. The reduction has given us a second-order difference equation in $Y_{1 t}$, with $X_{1 t}, X_{1 t-1}$ and $X_{2 t-1}$ as exogenous explanatory variables. In terms of evaluating whether equation (??) contains at least a significant subset of the information in system (??), we compute the roots of the second order difference equation in $Y$ (that is of $\left.Y_{1 t}=-115.35+1.847 Y_{1 t-1}-0.892 Y_{1 t-2}\right)$. These are:

$$
\lambda_{1,2}=0.9236 \pm 0.198 i
$$

The roots are essentially identical to the true values $(0.925 \pm 0.198 i)$. In terms of the coefficients, the reduction suggests that the coefficient, $\tilde{\theta}_{11}$ on $X_{1 t}$ should equal the true DGP value of $\theta_{11}=0.40$, which it does. 15 These results support the approach to the reduction of complex systems of first-order difference equations to a single higher order difference equation.

\subsection{Estimation}

It is well known that OLS estimation of dynamic panel data models with fixed $\mathrm{T}$ is biased such that the parameters $\phi_{s 1}, \phi_{s 2}, \phi_{s 3}$ and $\phi_{s 4}$ in (??) and $\phi_{h 1}$ $\phi_{h 2}, \phi_{h 3}$ and $\phi_{h 4}$ in (??) will be overestimated (?). Standard fixed effects estimation is downwardly biased. Instead estimation by the generalized method of moments (GMM) is favoured, constructing instruments for the lagged dependent variables, $\left(S_{i t-1}, S_{i t-2}, S_{i t-3}, S_{i t-4}\right)$ and $\left(H_{i t-1}, H_{i t-2}, H_{i t-3}, H_{i t-4}\right)$ from past values of the regressors (?). The standard approach to dealing with the individual fixed effect $\left(\mu_{i h}\right.$ and $\left.\mu_{i s}\right)$ is to first-difference the model. The additional serial correlation induced in the first-differenced error term informs the moment restriction imposed on the model and the choice of instruments. In

\footnotetext{
${ }^{15}$ We have also explored extending the simulation exercise to a system of four first-order difference equations, results are available upon request.
} 
the standard autoregressive dynamic panel data model with a single lag of the dependent variable, no exogenous regressors and no serial correlation in the error term in levels form, values of the dependent variable lagged two periods or more are valid instruments in the equation in first differences. For $T \geq 3$, there are $m=(T-2)(T-1) / 2$ moment restrictions of the form $E\left[Z_{i}^{\prime} \bar{\eta}_{i}\right]=0$ where $\bar{\eta}_{i}=\left(\bar{\eta}_{i 3} \cdots \bar{\eta}_{i T}\right)^{\prime}$ and $\bar{\eta}_{i t}=\eta_{i t}-\eta_{i t-1}$. These ideas naturally extend to the case of additional lags of the dependent variable and where serial correlation in the error exists in levels.

After first-differencing (??), the moment restrictions can be written in vector form as $E\left(Z_{i}^{\prime D} \Delta \epsilon_{i}\right)=0$, where $\Delta \epsilon_{i}=\left(\Delta \epsilon_{3 i}, \ldots, \Delta \epsilon_{i T}\right)^{\prime} . \Delta \epsilon_{i}=\epsilon_{i t}-\epsilon_{i t-1}$ and $Z_{i}^{D}$ is a block diagonal matrix whose $j t h$ block is given as (see Appendix B for details):

$$
\begin{aligned}
Z_{i}^{D}= & {\left[\operatorname{diag}\left(S_{i 1}, \ldots, S_{i s}\right) \vdots\left(\Delta X_{i 6}, \ldots, \Delta X_{i T}\right)^{\prime}\left(\Delta X_{i 5}, \ldots, \Delta X_{i T-1}\right)^{\prime}\right.} \\
& \left.\left(\Delta X_{i 4}, \ldots, \Delta X_{i T-2}\right)^{\prime}\left(\Delta X_{i 3}, \ldots, \Delta X_{i T-3}\right)^{\prime}\right] \\
& \text { for } s=1, \ldots, T-5 ; T \geq 6
\end{aligned}
$$

Accordingly, lags of the levels of the dependent variable form instruments for the difference model whilst the exogenous regressors act as instruments for themselves.

Due to weak instruments, the GMM estimation in first difference form can perform poorly where there exists higher-order autoregressive terms (persistence). ? suggest the use of a systems estimator that exploits additional moment conditions based on lagged differences of the dependent variable as instruments for a model in levels (also see ?). These additional moment conditions are valid under mean stationarity of the initial condition: $E\left(\mu_{i s} \Delta y_{i 2}\right)=0, \forall i$. 
Estimation in levels form also allows the identification of the coefficients on the time-invariant regressors, $W_{i}^{s}$ and $W_{i}^{h}$. As these are assumed to the uncorrelated with the individual unobserved effects they act as their own instruments for a model in levels. We follow this approach and estimate the fourth-order difference equations using system GMM. This approach effectively augments the above instrument set with a set of moment conditions $E\left[Z_{i}^{\prime L} \epsilon_{i}\right]=0$ where

$$
Z_{i}^{L}=\left[\operatorname{diag}\left(\Delta S_{i t-4}\right) \vdots\left(W_{i}^{s}\right)^{\prime}\right] \quad T \geq 6
$$

? show that these additional moment conditions are informative where data are persistent and instruments for the differenced equation are potentially weak, resulting in smaller finite sample bias and increased efficiency ${ }^{16}$

We begin by estimating the fourth-order difference equations set out in (??) and (??) using a systems GMM estimator with instruments defined in (??) and (??). Due to the length of panel observations available in the BHPS the set of instruments is large which can result in poor performance. Accordingly, we place restrictions on the instrument set to reduce its dimensionality by removing instruments further away from the observation period, $t$. Efficient two-step estimation applying Windmeijer's finite sample correction to the estimated variance is used (?). Specification tests of autocorrelation and the Sargan test of over-identifying restrictions are computed (see ?). In addition we compare GMM systems estimation to the within estimator (biased downwards) and OLS (biased upwards) ${ }^{17}$

\footnotetext{
${ }^{16}$ Note that further lagged differences of the dependent variable are redundant when combined with instruments for the first-differenced equation (see ?).

${ }^{17}$ We have explored specifications where lags of smoking and health enter the same equation as well as the joint estimation of a system of two second-order difference equations, each including lags of health and smoking. The former were estimated by employing a similar GMM approach and overall did not appear to produce reliable estimates if compared to their OLS-within fixed effects counterparts (estimates are available upon request). The latter was estimated via GMM three-stage least squares (3SLS) and failed to achieve convergence.
} 


\section{The British Household Panel Survey (BHPS)}

\subsection{Data and sample}

We estimate models on data drawn from 18 waves (1991 - 2009) of the British Household Panel Survey (BHPS). The BHPS is one of the longest and most comprehensive panel surveys currently available. The survey includes individual-level information on demographic and household characteristics; lifestyles including smoking habits; physical and mental health, wellbeing and the use of health care; education; job histories and interactions with the labour market as well as income and wealth. Its design and main content closely resemble those of other major panel data surveys such as the U.S. Panel Study of Income Dynamics (PSID) and the German Socio-Economic Panel (GSOEP). The BHPS initial sample (wave 1; 1991) consists of 5,500 private households and 10,264 individuals from England, Scotland and Wales 18 Original sample members are followed as they transit to different households and interviews are conducted annually to all adult individuals (aged 16 years or over), including new members of the households. Extension samples of around 1,500 households in each of Scotland and Wales and of 2,000 household from Northern Ireland were added in 1999 and 2001 respectively, making the BHPS representative of the whole UK 19

Our samples of interest consist of unbalanced panels of individuals who reported the consumption of cigarettes in at least one of the 18 waves of the survey. Never-smokers are excluded as such individuals tell us little about

\footnotetext{
${ }^{18}$ Before 1999 (wave 9), Scottish individuals were only sampled if they resided South of the Caledonian Canal.

${ }^{19}$ For further details on the BHPS sample structure, see ?.
} 
addictive behaviours. Within this sample, individuals for whom we observe sufficient data to estimate the model are included. Given the lag structure of the empirical model and the need to construct instruments from prior waves of data, this requires individuals to be observed for at least six consecutive waves ${ }^{20}$ Clearly, responses on individuals for whom we observe non-missing values on the set of variables of interest are included in the model. Accordingly, models for health are estimated on an unbalanced sample of 14,635 observations on 2,315 individuals for men and 17,674 observations on 2,701 individuals for women. Similarly, for smoking the respective samples are 18,407 observations on 2,864 individuals for men and 21,915 observations on 3,340 individuals for women.

\section{$5.2 \quad$ Smoking}

The BHPS contains two main self-reported indicators on smoking for adult individuals: smoking status and the daily number of cigarettes smoked. Information on smoking status is based on the question: "Do you smoke cigarettes?" from which we create a dummy variable taking value 1 if the individual is a smoker and 0 otherwise. Since the focus of our analysis is on addiction, our empirical models employ data on individuals who self-report being a smoker at least once during the period of the survey (potential smokers). Accordingly, we exclude individuals who reported not smoking throughout the 18 waves of the BHPS (see Table ?? for basic descriptive statistics for samples of interest). Information on the number of cigarettes smoked is derived from the following question "Approximately how many cigarettes a day do you usually smoke?". While this question is only asked to smokers, 0 is a possible answer that identi-

\footnotetext{
${ }^{20}$ The lag structure imposed by serial correlation in the error-term determines the exact number of lags required to construct valid instruments.
} 
fies occasional or social smokers (that is, individuals who defined themselves as smokers but report an average daily consumption of 0 cigarettes). Due to the heaping of responses that is typical of self-reported information on the quantity of cigarettes smoked (i.e. large number of responses concentrated at particular levels of smoking consumption), we recode consumption by considering multiples of five cigarettes (we refer to these as 'half packs').

\subsection{Health}

The BHPS contains a wide range of self-reported categorical variables of individual health status including the General Health Questionnaire (GHQ) on subjective well-being (?) and, in waves 9 and 14, the Short Form 36 (SF-36) health survey. The SF-36 is a standardised health questionnaire including 35 psychometric-validated questions about 8 different dimensions of both physical and mental health (physical functioning; role physical limitations; bodily pain; general health; mental health; vitality; social functioning; role emotional limitations) (Ware et al., 1993). Each dimension contains a set of items which present respondents with a series of choices about the perception of their own health. Information from all these health questions is used to build a summary measure of health, the SF-36 general index 21

We follow ? and use selected questions from six of the original eight dimensions of the SF-36 (physical functioning; role limitations; social functioning; bodily pain; mental health; vitality) to build a preference-based index measure of health called the SF-6D that is defined on a continuous scale ranging between 0 (an health state equivalent to death) to 1 (full health) ${ }^{22}$ More

\footnotetext{
${ }^{21}$ Additional and updated information on the SF-36 and its related literature are available on the SF-36 community web page (http://www.sf-36.org).

${ }^{22}$ As specified in ?, to build the SF-6D (where 6D stands for six dimensions) they have excluded general health items and collapsed the two dimensions of role limitations due to physical and emotional problems into a single role limitations dimension.
} 
specifically, Brazier et al. employed health information from selected items of these six dimensions and combine it with health state utility values to define a utility-based measure of health. Health utility values were retrieved through a preference-based valuation survey of the UK general population. We apply these weights on the items from the six dimensions of the SF-36 to generate SF-6D values for individuals in waves 9 and 14 of the BHPS. In order to recover SF-6D values for all individuals in each wave, we regress SF-6D values onto the BHPS specific health conditions dummy variables ${ }^{23}$ present in all waves of data together with dummy variables derived from the general SAH measure (excellent, fair, poor/very poor health leaving good/very good health as baseline) using pooled Ordinary Least Square (OLS). We estimate separate models for men and women and use the predicted SF-6D scores from these regressions as our measure of health in our main empirical specifications ${ }^{25}$ In this way, we obtain a cardinal measure of health for all individuals in our survey, defined on a continuous scale from 0 to 1 which is used as our empirical proxy of health capital. As the measure draws from a wide range of health domains we feel that it better approximates the notion of health capital as originally defined in the Grossman model.

\footnotetext{
${ }^{23}$ These cover problems related to arms, legs or hands, sight, hearing, skin conditions, chest/breathing, heart/blood pressure, stomach or digestion, diabetes, anxiety/depression, alcohol or drug use, epilepsy, migraine.

${ }^{24}$ Due to a change in wording and response categories in the SAH question at wave 9 , we collapse the original five category self-assessed variable (SAH) to a four category measure. In waves 1-8 and 10-18, respondents are asked: Compared to people of your own age, would you say your health over the last 12 months on the whole has been: excellent, good, fair, poor or very poor?, whereas in wave 9 , the question and possible answers are: In general, would you say your health is: excellent, very good, good, fair, poor?. Creating a SAH variable with four health categories (excellent, good or very good, fair, poor or very poor) allows common support over the two versions of the question.

${ }^{25}$ We have also employed alternative specifications to compute predicted SF-6D values for all individuals in the sample such as linear fixed effects models. We have also estimated versions of these models (pooled OLS and linear fixed effects models) with lagged values of all regressors (health variables) to ease potential problems related to endogeneity. As predicted SF-6D scores and results from the main dynamic empirical models of health capital and smoking do not appear to differ across these specifications; we use results from the simple pooled OLS models to maximise the number of observations.
} 


\subsection{Socio-economic and demographic variables}

\subsubsection{Time-varying regressors}

Our dynamic models of health and smoking are estimated separately for men and women and are conditioned on age and age squared; household characteristics (being married or cohabiting, household size and the number of cohabiting children); labour status (employed, self-employed, unemployed, retired, longterm sick/disability status and other employment ${ }^{26}$ with employed as an employee as the baseline and household income (equivalised annual log-household income). In order to account for the effects of health shocks on both smoking preferences and health status, we include a dummy variable defining the presence of health shocks/accidents that led to hospitalisation in the previous year.

\subsubsection{Time-invariant regressors}

In addition to the set of regressors outlined above, we include a set of timeinvariant variables for highest attained educational qualification (in descending order: degree or higher degree, HND or A-level, O-level or CSE, versus no qualification), ethnicity (categorised as white versus non-white) and a set of region of residence dummy variables. ${ }^{27}$

In addition, a vector of year dummies is included in all models to account for aggregate health shocks, time-varying reporting changes, trends in smoking incidence and prevalence and any effects of ageing not captured by the age

\footnotetext{
${ }^{26}$ Other employment consists of looking after the family, maternity leave, government training, student or other jobs.

${ }^{27}$ The set of regional dummy variables contains little variation across the waves and accordingly these are categorised as the region in which a respondent was observed to reside the longest. The regions cover England (South East, South West, London, Midlands, Yorkshire, North West, North East), Scotland, Wales and Northern Ireland. The South East is taken as the baseline.
} 
variables.

Descriptive statistics for the set of explanatory variables are presented in Table ?? separately for men and women. To save space these are presented for the sub-sample of individuals used in the estimation of the smoking models. These models contain a larger number of respondents than the corresponding health equation. On average men smoke more cigarettes per day than women (2.234 versus 2.123 half-packs respectively) and report better health status (0.810 versus 0.785$)$. The two samples are of similar mean age. Men are more likely to be married or cohabiting, and more likely to be employed or selfemployed than women. Women are more likely to be catergorised as other employed or retired than men. A larger proportion of men have a degree or higher degree, or HND/A-level qualification compared to the sample of women. Men report a higher household income than women and more health shocks and/or accidents resulting in hospitalisation. A larger proportion of women in the sample report being white or other ethnic origin.

\section{Results}

\subsection{Regression models}

Table ?? for men and Table ?? for women summarise our estimation results separately for models for health and smoking. The first column presents OLS estimates of models (??) and (??) above, applying robust standard errors to capture general forms of heteroscedasticity. OLS estimation of dynamic panel data models are biased upwards $((?))$, however, the estimated coefficients on the lags of the dependent variable exhibit clear and strong gradients for both health and smoking. While our estimates represent composite parameters, it is worth noting that state dependence in smoking and health outcomes have 
been observed elsewhere (for example, ???). The second column presents corresponding estimates from within (fixed effects) estimation. These are biased downwards and while showing a gradient across the lagged terms, the effects are smaller than corresponding OLS estimates and are less significant statistically.

The third column presents results of system GMM estimation of models (??) and (??). Given the moving-average of order 3 in the errors, instruments are constructed from observations of the dependent variable from period $t-5$ and before for the model in first-differenced form. Estimated coefficients are expected to fall between OLS and within estimation. Estimation was performed by varying the maximum number of lags of the dependent variable from which to define instruments, and results reported for the specification that produced the most credible estimates. This decision was based on the Sargan test for over-identification, tests for serial correlation and judgement on the resulting estimates. For example, coefficients closer to within than OLS estimation may be indicative of weak instruments. For men, instruments were constructed from observations between 5 and 6 lagged periods for health and 5 and 7 lagged periods for smoking. For women these were between 5 and 8 lagged periods for both health and smoking models. Given the long lag period required to construct instruments, it is not surprising that the resulting instruments are weak leading to estimated coefficients on the lags of the dependent variable lying outside the range of OLS and within estimation. This holds for the majority of estimates across both health and smoking models, for both men and women. These estimates are not reliable.

Tests for serial correlation in first-differenced form reveal, in general, correlation of order 1 (reported in Tables ?? and ??). This corresponds to a lack of 
moving average terms in the levels error structure of (??) and (??) ${ }^{28}$ Imposing the restriction that $\rho_{\epsilon 1}, \rho_{\epsilon 2}, \rho_{\epsilon 3}=0$ in (??), and $\rho_{\varepsilon 1}, \rho_{\varepsilon 2}, \rho_{\varepsilon 3}=0$ in (??) the respective error terms can simply be represented as $\epsilon_{i t}$ and $\varepsilon_{i t}$. These restrictions free up instruments from periods closer to lags of the dependent variable, $S_{i t-1}, \ldots, S_{i t-4}$, and $H_{i t-1}, \ldots, H_{i t-4}$. More recent lags are likely to have greater predictive power and hence greater relevance as instruments than those constructed from periods further away from the lagged terms ${ }^{29}$ Column 4 presents GMM system results assuming a lack of a moving average process $(\mathrm{MA}(0))$ in the level's error. For models of both health and smoking, and for men and women, this specification is supported by tests for first-order serial correlation in first-differenced form and Sargan tests for overidentification.Parameter estimates on the lags of the dependent variable lie between OLS and within estimates and generally are closer to the former. For women, all lagged terms are significant at conventional (5\%) levels; for men, the first three lags are significant. These results indicate strong and enduring persistence in the evolution of both health capital and smoking consumption with direct effects on current health and smoking observed for up to three and four lagged periods for men and women respectively.

All models contain contemporaneous values of the set of exogenous regressors $X_{i t}$ and their corresponding lags: $X_{i t-1}, X_{i t-2}, X_{i t-3}$, together with the set of time-invariant regressors, $W_{i}$, and a vector of year dummy variables. Many of the regressors, $X_{i t}$, display little variation over time (for example, marital status, employment status) and accordingly suffer from collinearity. Few of the lagged terms are significant in the model presented in column 430 To simplify

\footnotetext{
${ }^{28}$ It is plausible that the inclusion of higher order dynamics via four lags in our models may absorb any remaining serial correlation in the disturbances.

${ }^{29} S_{i t-2}, \ldots, S_{i t 1}$ are potential instruments for $\Delta S_{i t-1}, \ldots, \Delta S_{i t-4}$. Similarly, for $\Delta H_{i t-1}, \ldots, \Delta H_{i t-4}$.

${ }^{30}$ These results are available on request.
} 
the interpretation of the effects of these regressors, we restrict the coefficients on the lagged terms to be zero. This results in estimates presented in column 5. Again, the models pass relevant specification tests and the coefficients on the lagged dependent terms do not change substantively from those of column 4.

Table ?? presents estimated coefficients for the set of covariates $X_{i t}$ and $W_{i} \cdot{ }^{31}$ For men, larger household income is associated with increased health and other employment is associated with decreased health (at the $6 \%$ significance level). Interestingly individuals who reported an accident leading to a hospitalization report better health than those not reporting an accident. Living in the South West (compared to the South East) is associated with decreased health status (at the 10\% level). For women, lower health status is reported for those living in Yorkshire (at 10\%), the North West, the North East, Scotland, Wales and Northern Ireland (at the $6 \%$ significance level) compared to the South East. Again an accident in the previous twelve months is associated with reporting higher health status. For male ever smokers, being unemployed (at the $5 \%$ level) or other employment is associated with lower consumption of cigarettes (at the $10 \%$ level) as is being married or cohabiting (at the 10\% level). Men living in Scotland, Wales and Northern Ireland report higher consumption than men living in the South East (all at 5\% significance). Being married or cohabiting is also associated with lower levels of smoking for women, while a greater number of children is associated with higher smoking prevalence. Being self-employed is also associated with a higher consumption of cigarettes (at the 10\% level). For women there is a clear educational gradient with higher educated individuals smoking less than lower educated individuals (baseline is no qualifications). These effects are highly significant. Women

\footnotetext{
${ }^{31}$ The year dummies, which are not reported, indicate a decreasing trend in smoking across the waves for men but not for women and no discernible trends for health.
} 
belonging to non-white ethnic groups smoke less than their white couterparts. There are also clear regional effects, with women living in the North West, North East, Scotland, and Wales all reporting higher levels of cigarette consumption than those living in the South East of England.

\subsection{Characteristic roots}

The observed evolution of an individual's stock of health (or smoking) will depend in part on changes in exogenous variables and in part on the intrinsic dynamics inherent in their optimal lifetime trajectory. That trajectory is characterized by what is sometimes referred to as path dependence, conditional on the values of the exogenous variables. Whether any series of observations on $H$ (or $S$ ) are on the same trajectory depends on the frequency with which the exogenous variables cause the trajectory to shift. The trend along this trajectory is in most cases non-linear. The presence of the exogenous explanatory variables in the equation means that we do a better job of estimating the characteristics of the lifetime trajectory, since they will control for shifts in the trajectory which are due to changes in the value of the exogenous variables. At the same time controlling for the natural tendency of the variable in question to evolve over time means that our estimation of the coefficients on the exogenous variables will be more efficient.

The intrinsic dynamics of $H$ and $S$ are characterised by four roots. For men the health equation has roots: $0.787,-0.363$, and $-0.026 \pm 0.417$. For men smoking the roots are: $0.809,-0.225$, and $-0.04 \pm 0.294$. Since the roots are highly non-linear combinations of the coefficients we cannot test the hypothesis that the corresponding roots match across the equations, as should be the case given our theoretical structure. Instead we comment on the general pattern of the results. 
Both equations have two real and two complex roots. The dominant real roots which drive the long term behaviour of the variables for health and smoking are both positive and less than one in absolute value, and are, numerically very similar. The second real roots are both negative, both less than 1 in absolute value and of similar magnitude across the equations. While negative roots are unusual in economic models, they can arise in empirical applications simply as a consequence of the evolution of the variable in question between observation points. The final two roots are, in each equation, complex conjugate pairs, implying a cyclical element to the trajectory. The modulus of the complex roots in the health equation is 0.418 and in the smoking equation 0.297. The general pattern of the trajectories across the two equations are, therefore, fairly similar, particularly with respect to the dominant root.

For the health equation for women, the roots are: 0.791, -0.409 , and $-0.014 \pm 0.412$, and for smoking: $0.812,-0.349$, and $-0.002 \pm 0.356$. Again the dominant roots are very similar across the pair of equations (and very similar to the dominant roots in the male equations, which is not required by the model). The second real root is negative in each equation, less than 1 in absolute value and reasonably similar across the equations, and the final pairs are complex conjugates. In the health equation for women the modulus of the complex roots is 0.412 and in the smoking equation; 0.356 .

\section{Conclusions and Discussion}

This paper presents a dynamic panel data estimation of an integrated Grossman-B-M model of health and smoking. We employ mature British panel data containing up to eighteen waves of data on any given survey respondent. This allows us to robustly estimate an empirical specification containing struc- 
tural dynamic elements derived directly from a theoretical model that combines Grossman's concept of health investment with the B-M model. In turn, this allows greater understanding of the inherent dynamics of the model, but also the impact of exogenous variables assumed to shift an individual's optimal trajectory.

It is important to note here that we are not dealing with macro data, or even market level data, in which variables are likely to be trended, either exogenously or through the presence of a unit root. While our dominant roots are reasonably large, and although lack of standard errors means that we cannot formally test them against unity, there does not appear to be a nonstationarity problem in our data. The lagged dependent variables in this type of equation are representations of intrinsic features of an individual's optimal trajectory.

Conditional on the intrinsic dynamics in the health and smoking equations, few of the coefficients on the exogenous explanatory variables are statistically significant. For men higher household income is associated with being healthier while for women health appears independent of income. These small impacts of income on health appear to corroborate findings elsewhere on the relationship between income and health. For instance, using the fall of the Berlin Wall as a natural experiment to study the impact of rapid increases in income for East Germans following reunification, ?, found a similarly small impact on men and reported no effect for women. ? and ? also report small gradients in the income-health relationship.

Interestingly, highest educational qualifications while generally displaying the expected gradients for health (positive) for women, is not statistically significant. While this is contrary to theoretical predictions from the pure Grossman model (?), this finding is supported by those of ? who also con- 
clude that education, conditional on socio-economic status (wealth), is not systematically associated with health. Education does, however, display a more pronounced gradient for smoking with effects greater (and statistically significant) for women compared to men. Being married or cohabiting is associated with smoking less for both men and women; a results observed elsewhere (?). Non-white ethnicity is significantly associated with reduced daily smoking for women. In general, for both men and women non-white ethnic groups have a lower prevalence of smoking than white ethnic groups, although this masks important variation across minority groups which is more pronounced for women than for men. 32

One result that may appear surprising is the general lack of significance of the terms for age. We typically expect age to play a significant role, at least in an equation for health. In other empirical work, especially studies relying on cross-section data and to a slightly lesser extent very short panel data studies, age has acted as a proxy for the stage of an individual along her lifetime trajectory. Given the tendency of that trajectory to non-linearity, age works best as a proxy when entered as a polynomial. In Grossman's theoretical model, the rate of depreciation of health capital increases with age. This increase will tend to cause the individual's stock of health capital to decline faster in later years than in earlier years, but the individual may respond by increasing her investment in health to slow the rate of decline of $H$. This is part of the process by which the optimizing individual contrives to follow the optimal lifetime trajectory for health capital. Given that we have incorporated the shape of the trajectory directly into the estimation by running fourth order

\footnotetext{
${ }^{32}$ For example, it has been reported elsewhere that Black-Caribbean and Other South Asian women have a far greater prevalence of regular smoking (at levels slightly lower than white ethnic groups) compared to Bangladeshi, Indian, Pakistani, Chinese and other Black minority ethnic groups (?). There is evidence of geographical variation, particularly for women where areas associated with decreased health (compared to the baseline of South East of England) are also associated with increased smoking.
} 
difference equations, there remains little role for age to play. ${ }^{33}$

A more accurate inference of the integrated life-cycle model proposed here would imply the use of a structural approach. Although this would have the advantage of identifying more precisely the different structural components, it would require a substantially more complex and computationally intensive estimation strategy. We believe that our reduced-form estimation may provide a viable alternative in the presence of long panel data, especially if the main interest of the researcher is to explore the dynamics of this type of life-cycle models.

\footnotetext{
${ }^{33}$ Of the remaining variables, the lack of significance may well be a consequence of a lack of within-individual variation. Alternatively it may indicate that these variables do not have a role in shifting the optimal trajectory for an individual. If these are variables which do not change often and which have relatively small impacts on the position of the individual's optimal trajectory, it is not surprising that, conditional on the intrinsic dynamics, they do not appear important.
} 
(1)

$(2)$

\begin{tabular}{lccclcc}
$Y_{1 t}$ & True & MC & MC & $Y_{1 t}$ & MC & MC \\
Parameter & Value & Coef & SE & Parameter & Coef & SE \\
\hline \hline & & & & & & \\
$\phi_{10}$ & 100 & 99.99 & 1.15 & $\tilde{\phi}_{10}$ & -115.35 & 0.612 \\
$\phi_{11}$ & 0.9 & 0.899 & 0.000 & $\tilde{\phi}_{11}$ & 1.847 & 0.001 \\
$\phi_{12}$ & -0.4 & -0.400 & 0.001 & $\tilde{\phi}_{12}$ & -0.892 & 0.001 \\
$\theta_{11}$ & 0.4 & 0.401 & 0.022 & $\tilde{\theta}_{11}$ & 0.399 & 0.040 \\
$\theta_{12}$ & 0.0 & $-0.47 e^{-005}$ & 0.026 & $\tilde{\theta}_{12}$ & -0.379 & 0.040 \\
$Y_{2 t}$ & & & & $\tilde{\theta}_{13}$ & -0.241 & 0.030 \\
Parameter & & & & & & \\
$\phi_{20}$ & 300 & 300.02 & 1.192 & & & \\
$\phi_{21}$ & 0.1 & 0.099 & 0.000 & & & \\
$\phi_{22}$ & 0.95 & 0.949 & 0.000 & & & \\
$\theta_{21}$ & 0.0 & 0.000 & 0.022 & & & \\
$\theta_{22}$ & 0.4 & 0.599 & 0.025 & & & \\
\hline
\end{tabular}

Table 1: Summary Monte Carlo results. Based on $M=1000$ MC repetitions, with $N=500$ random draws with replacement. Simulations in column (1) based on the system of equations (??) and (??) with parameters set at 'True value'; Simulations in column (2) based on MC estimation of equation (??). MC estimated coefficients and standard errors reported. 


\begin{tabular}{|l|c|c|c|c|c|c|c|c|}
\hline & \multicolumn{7}{|c|}{ NTen } & \multicolumn{4}{c|}{ NT $=21915$} \\
Variables & \multicolumn{3}{|c|}{ NT 18407} & \multicolumn{3}{c|}{ Nomen } \\
\hline Cigarettes (1/2 packs) & 2.234 & 2.096 & 0 & 9 & 2.123 & 1.862 & 0 & 9 \\
Health & 0.810 & 0.070 & 0.462 & 0.908 & 0.785 & 0.080 & 0.467 & 0.899 \\
Age & 45.25 & 15.96 & 19 & 98 & 45.26 & 15.98 & 19 & 96 \\
Married/Co-habiting & 0.710 & 0.454 & 0 & 1 & 0.632 & 0.482 & 0 & 1 \\
Household Size & 2.866 & 1.398 & 1 & 16 & 2.806 & 1.333 & 1 & 16 \\
Number of Children & 0.565 & 0.978 & 0 & 7 & 0.655 & 0.995 & 0 & 8 \\
Employed & 0.568 & 0.495 & 0 & 1 & 0.517 & 0.500 & 0 & 1 \\
Unemployed & 0.058 & 0.223 & 0 & 1 & 0.030 & 0.171 & 0 & 1 \\
Self Employed & 0.115 & 0.319 & 0 & 1 & 0.036 & 0.187 & 0 & 1 \\
Retired & 0.156 & 0.363 & 0 & 1 & 0.173 & 0.378 & 0 & 1 \\
Employment other & 0.089 & 0.284 & 0 & 1 & 0.227 & 0.419 & 0 & 1 \\
Long-term sick & 0.014 & 0.119 & 0 & 1 & 0.016 & 0.127 & 0 & 1 \\
Log Household Income & 9.636 & 0.646 & -0.350 & 12.914 & 9.552 & 0.637 & -0.174 & 13.505 \\
Accidents & 0.119 & 0.284 & 0 & 1 & 0.087 & 0.283 & 0 & 1 \\
Degree/Higher degree & 0.104 & 0.443 & 0 & 1 & 0.095 & 0.293 & 0 & 1 \\
HND/A-Level & 0.268 & 0.443 & 0 & 1 & 0.191 & 0.393 & 0 & 1 \\
O-Level/ CSE & 0.304 & 0.460 & 0 & 1 & 0.344 & 0.475 & 0 & 1 \\
No Qualifications & 0.324 & 0.468 & 0 & 1 & 0.371 & 0.483 & 0 & 1 \\
White & 0.970 & 0.170 & 0 & 1 & 0.987 & 0.111 & 0 & 1 \\
Non-White & 0.030 & 0.170 & 0 & 1 & 0.013 & 0.111 & 0 & 1 \\
South East & 0.149 & 0.356 & 0 & 1 & 0.148 & 0.355 & 0 & 1 \\
South West & 0.068 & 0.253 & 0 & 1 & 0.062 & 0.240 & 0 & 1 \\
London & 0.074 & 0.261 & 0 & 1 & 0.067 & 0.250 & 0 & 1 \\
Midlands & 0.193 & 0.395 & 0 & 1 & 0.169 & 0.375 & 0 & 1 \\
Yorkshire & 0.082 & 0.275 & 0 & 1 & 0.081 & 0.273 & 0 & 1 \\
North West & 0.091 & 0.288 & 0 & 1 & 0.094 & 0.292 & 0 & 1 \\
North East & 0.045 & 0.207 & 0 & 1 & 0.054 & 0.225 & 0 & 1 \\
Scotland & 0.133 & 0.340 & 0 & 1 & 0.149 & 0.356 & 0 & 1 \\
Wales & 0.110 & 0.313 & 0 & 1 & 0.111 & 0.314 & 0 & 1 \\
Northern Ireland & 0.054 & 0.227 & 0 & 1 & 0.066 & 0.248 & 0 & 1 \\
\hline
\end{tabular}

Table 2: Descriptive statistics. Sample based on Smoking equations (NT $=18407$ for men and NT $=21915$ for women, except for the health variable $(\mathrm{NT}=17918$ for men and $\mathrm{NT}=21429$ for women 


\begin{tabular}{|c|c|c|c|c|c|}
\hline \multirow[t]{2}{*}{ Health } & \multirow{2}{*}{$\begin{array}{l}\text { OLS } \\
(1) \\
\end{array}$} & \multirow{2}{*}{$\begin{array}{c}\text { Within } \\
(2)\end{array}$} & \multicolumn{3}{|c|}{ System GMM } \\
\hline & & & $\begin{array}{c}\mathrm{MA}(3) \\
(3)\end{array}$ & $\begin{array}{c}\mathrm{MA}(0) \\
(4)\end{array}$ & $\begin{array}{c}\mathrm{MA}(0) \\
(5)\end{array}$ \\
\hline$H_{i t-1}$ & $0.412(0.000)$ & $0.122(0.000)$ & $0.510(0.014)$ & $0.367(0.000)$ & $0.372(0.000)$ \\
\hline$H_{i t-2}$ & $0.177(0.000)$ & $-0.001(0.918)$ & $0.340(0.093)$ & $0.133(0.000)$ & $0.132(0.000)$ \\
\hline$H_{i t-3}$ & $0.140(0.000)$ & $-0.007(0.573)$ & $0.226(0.178)$ & $0.087(0.002)$ & $0.088(0.001)$ \\
\hline$H_{i t-4}$ & $0.104(0.000)$ & $-0.040(0.000)$ & $-0.062(0.104)$ & $0.043(0.220)$ & $0.051(0.128)$ \\
\hline$X_{i t}$ & $\mathrm{Y}$ & $\mathrm{Y}$ & $\mathrm{Y}$ & $\mathrm{Y}$ & $\mathrm{Y}$ \\
\hline$X_{i t-1}$ & Y & Y & $\mathrm{Y}$ & Y & $\mathrm{N}$ \\
\hline$X_{i t-2}$ & Y & Y & Y & Y & $\mathrm{N}$ \\
\hline$X_{i t-3}$ & Y & Y & $\mathrm{Y}$ & Y & $\mathrm{N}$ \\
\hline$W_{i}$ & Y & $\mathrm{N}$ & Y & $\mathrm{Y}$ & $\mathrm{Y}$ \\
\hline Years & $\mathrm{Y}$ & $\mathrm{Y}$ & $\mathrm{Y}$ & $\mathrm{Y}$ & $\mathrm{Y}$ \\
\hline $\mathrm{NT}(\mathrm{N})$ & $14635(2315)$ & $14635(2315)$ & $14635(2315)$ & $14635(2315)$ & $14635(2315)$ \\
\hline Sargan test & & & $22.7[31](0.858)$ & $52.0[45](0.220)$ & $51.4[45](0.238)$ \\
\hline Serial Corr: & & & & & \\
\hline Order (1) & & & $-2.22(0.026)$ & $-20.2(0.000)$ & $-20.42(0.000)$ \\
\hline Order (2) & & & $-0.29(0.771)$ & $0.30(0.763)$ & $0.32(0.749)$ \\
\hline Order (3) & & & $-0.67(0.502)$ & & \\
\hline Order (4) & & & $1.25(0.210)$ & & \\
\hline Order (5) & & & $1.20(0.229)$ & & \\
\hline Lags: & & & $(56)$ & $(24)$ & $(24)$ \\
\hline \multirow[t]{2}{*}{ Smoking } & \multirow[t]{2}{*}{ OLS } & \multirow[t]{2}{*}{ Within } & \multicolumn{3}{|c|}{ System GMM } \\
\hline & & & $\mathrm{MA}(3)$ & $\operatorname{MA}(0)$ & $\mathrm{MA}(0)$ \\
\hline$\overline{S_{i t-1}}$ & $0.540(0.000)$ & $0.296(0.000)$ & $0.360(0.087)$ & $0.509(0.000)$ & $0.504(0.000)$ \\
\hline$S_{i t-2}$ & $0.181(0.000)$ & $0.063(0.000)$ & $0.461(0.003)$ & $0.143(0.000)$ & $0.142(0.000)$ \\
\hline$S_{i t-3}$ & $0.093(0.000)$ & $0.011(0.327)$ & $-0.046(0.775)$ & $0.067(0.000)$ & $0.066(0.000)$ \\
\hline$S_{i t-4}$ & $0.066(0.000)$ & $-0.023(0.024)$ & $0.034(0.405)$ & $0.016(0.231)$ & $0.016(0.250)$ \\
\hline$X_{i t}$ & $\mathrm{Y}$ & $\mathrm{Y}$ & $\mathrm{Y}$ & $\mathrm{Y}$ & $\mathrm{Y}$ \\
\hline$X_{i t-1}$ & Y & Y & Y & Y & $\mathrm{N}$ \\
\hline$X_{i t-2}$ & Y & Y & Y & Y & $\mathrm{N}$ \\
\hline$X_{i t-3}$ & Y & Y & Y & Y & $\mathrm{N}$ \\
\hline$W_{i}$ & Y & $\mathrm{N}$ & Y & Y & $\mathrm{Y}$ \\
\hline Years & $\mathrm{Y}$ & $\mathrm{Y}$ & $\mathrm{Y}$ & $\mathrm{Y}$ & $\mathrm{Y}$ \\
\hline NT (N) & $18407(2864)$ & $18407(2864)$ & $18407(2864)$ & $18407(2864)$ & $18407(2864)$ \\
\hline Sargan test & & & $34.7[45](0.867)$ & $76.7[62](0.099)$ & $74.7[62](0.130)$ \\
\hline Serial Corr: & & & & & \\
\hline Order (1) & & & $-2.18(0.029)$ & $-20.78(0.000)$ & $-20.74(0.000)$ \\
\hline Order (2) & & & $-2.94(0.003)$ & $1.07(0.283)$ & $0.92(0.359)$ \\
\hline Order (3) & & & $1.29(0.198)$ & & \\
\hline Order (4) & & & $-0.29(0.771)$ & & \\
\hline Order (5) & & & $0.64(0.519)$ & & \\
\hline Lags: & & & $(57)$ & $(25)$ & $(25)$ \\
\hline
\end{tabular}

Table 3: Men: Fourth-order single equation estimates. Coefficient estimates and p-values in parentheses. The Sargan test reports the statistic, degrees of freedom [ ] and associated p-value ( ). Tests for serial correlation in first-differenced errors report the test statistic and p-value ( ). Lags reports the lag structure used to construct instruments for the model in first-differened form. Two-step robust standard errors are used (?). 


\begin{tabular}{|c|c|c|c|c|c|}
\hline \multirow[t]{2}{*}{ Health } & \multirow{2}{*}{$\begin{array}{l}\text { OLS } \\
(1) \\
\end{array}$} & \multirow{2}{*}{$\begin{array}{c}\text { Within } \\
(2)\end{array}$} & \multicolumn{3}{|c|}{ System GMM } \\
\hline & & & $\begin{array}{c}\mathrm{MA}(3) \\
(3)\end{array}$ & $\begin{array}{c}\mathrm{MA}(0) \\
(4)\end{array}$ & $\begin{array}{c}\mathrm{MA}(0) \\
(5)\end{array}$ \\
\hline$H_{i t-1}$ & $0.407(0.000)$ & $0.119(0.000)$ & $0.403(0.009)$ & $0.341(0.000)$ & $0.355(0.000)$ \\
\hline$H_{i t-2}$ & $0.200(0.000)$ & $0.015(0.144)$ & $0.205(0.160)$ & $0.158(0.000)$ & $0.164(0.000)$ \\
\hline$H_{i t-3}$ & $0.131(0.000)$ & $-0.015(0.124)$ & $0.131(0.335)$ & $0.070(0.000)$ & $0.074(0.000)$ \\
\hline$H_{i t-4}$ & $0.125(0.000)$ & $-0.021(0.034)$ & $0.023(0.358)$ & $0.051(0.001)$ & $0.055(0.000)$ \\
\hline$X_{i t}$ & $\mathrm{Y}$ & $\mathrm{Y}$ & $\mathrm{Y}$ & $\mathrm{Y}$ & $\mathrm{Y}$ \\
\hline$X_{i t-1}$ & Y & Y & $\mathrm{Y}$ & $\mathrm{Y}$ & $\mathrm{N}$ \\
\hline$X_{i t-2}$ & Y & Y & Y & Y & $\mathrm{N}$ \\
\hline$X_{i t-3}$ & Y & Y & $\mathrm{Y}$ & $\mathrm{Y}$ & $\mathrm{N}$ \\
\hline$W_{i}$ & Y & $\mathrm{N}$ & Y & $\mathrm{Y}$ & $\mathrm{Y}$ \\
\hline Years & $\mathrm{Y}$ & $\mathrm{Y}$ & $\mathrm{Y}$ & $\mathrm{Y}$ & $\mathrm{Y}$ \\
\hline $\mathrm{NT}(\mathrm{N})$ & $17674(2701)$ & $17674(2701)$ & $17674(2701)$ & $17674(2701)$ & $17674(2701)$ \\
\hline Sargan test & & & $48.3[50](0.543)$ & $80.2[68](0.149)$ & $79.0[68](0.170)$ \\
\hline Serial Corr: & & & & & \\
\hline Order (1) & & & $-4.11(0.000)$ & $-25.03(0.000)$ & $-25.01(0.000)$ \\
\hline Order (2) & & & $0.10(0.920)$ & $0.16(0.873)$ & $0.05(0.961)$ \\
\hline Order (3) & & & $-0.41(0.684)$ & & \\
\hline Order (4) & & & $0.60(0.552)$ & & \\
\hline Order (5) & & & $-0.40(0.687)$ & & \\
\hline Lags: & & & $(58)$ & $(26)$ & $(26)$ \\
\hline \multirow[t]{2}{*}{ Smoking } & \multirow[t]{2}{*}{ OLS } & \multirow[t]{2}{*}{ Within } & \multicolumn{3}{|c|}{ System GMM } \\
\hline & & & $\mathrm{MA}(3)$ & $\operatorname{MA}(0)$ & $\mathrm{MA}(0)$ \\
\hline$S_{i t-1}$ & $0.520(0.000)$ & $0.265(0.000)$ & $0.171(0.412)$ & $0.457(0.000)$ & $0.458(0.000)$ \\
\hline$S_{i t-2}$ & $0.198(0.000)$ & $0.075(0.000)$ & $0.488(0.024)$ & $0.159(0.000)$ & $0.159(0.000)$ \\
\hline$S_{i t-3}$ & $0.098(0.000)$ & $0.012(0.219)$ & $0.077(0.624)$ & $0.060(0.000)$ & $0.060(0.000)$ \\
\hline$S_{i t-4}$ & $0.078(0.000)$ & $-0.010(0.292)$ & $0.003(0.931)$ & $0.034(0.004)$ & $0.037(0.001)$ \\
\hline$X_{i t}$ & $\mathrm{Y}$ & $\mathrm{Y}$ & $\mathrm{Y}$ & $\mathrm{Y}$ & $\mathrm{Y}$ \\
\hline$X_{i t-1}$ & Y & Y & $\mathrm{Y}$ & Y & $\mathrm{N}$ \\
\hline$X_{i t-2}$ & Y & Y & $\mathrm{Y}$ & Y & $\mathrm{N}$ \\
\hline$X_{i t-3}$ & Y & Y & Y & Y & $\mathrm{N}$ \\
\hline$W_{i}$ & Y & $\mathrm{N}$ & Y & Y & $\mathrm{Y}$ \\
\hline Years & $\mathrm{Y}$ & $\mathrm{Y}$ & $\mathrm{Y}$ & $\mathrm{Y}$ & $\mathrm{Y}$ \\
\hline NT (N) & $21915(3340)$ & $21915(3340)$ & $21915(3340)$ & $21915(3340)$ & $21915(3340)$ \\
\hline Sargan test & & & $24.4[34](0.887)$ & $63.4[74](0.804)$ & $62.0[74](0.838)$ \\
\hline Serial Corr: & & & & & \\
\hline Order (1) & & & $-1.95(0.052)$ & $-21.98(0.000)$ & $-22.13(0.000)$ \\
\hline Order (2) & & & $-2.42(0.016)$ & $-0.95(0.344)$ & $-0.96(0.339)$ \\
\hline Order (3) & & & $0.46(0.644)$ & & \\
\hline Order (4) & & & $0.38(0.707)$ & & \\
\hline Order (5) & & & $1.17(0.240)$ & & \\
\hline Lags: & & & $(58)$ & $(26)$ & $(26)$ \\
\hline
\end{tabular}

Table 4: Women: Fourth-order single equation estimates. Coefficient estimates and p-values in parentheses. The Sargan test reports the statistic, degrees of freedom [ ] and associated p-value ( ). Tests for serial correlation in first-differenced errors report the test statistic and p-value ( ). Lags reports the lag structure used to construct instruments for the model in first-differened form. Two-step robust standard errors are used (?). 


\begin{tabular}{|c|c|c|c|c|c|c|c|c|}
\hline & \multicolumn{4}{|c|}{ Men } & \multicolumn{4}{|c|}{ Women } \\
\hline & \multicolumn{2}{|c|}{$\begin{array}{c}\text { Health } \\
\mathrm{NT}=14635\end{array}$} & \multicolumn{2}{|c|}{$\begin{array}{c}\text { Smoking } \\
\mathrm{NT}=18407\end{array}$} & \multicolumn{2}{|c|}{$\begin{array}{c}\text { Health } \\
\mathrm{NT}=17674\end{array}$} & \multicolumn{2}{|c|}{$\begin{array}{c}\text { Smoking } \\
\mathrm{NT}=21915\end{array}$} \\
\hline$Y_{i t-1}$ & 0.372 & $(0.000)$ & 0.504 & $(0.000)$ & 0.355 & $(0.000)$ & 0.458 & $(0.000)$ \\
\hline$Y_{i t-2}$ & 0.132 & $(0.000)$ & 0.142 & $(0.000)$ & 0.164 & $(0.000)$ & 0.159 & $(0.000)$ \\
\hline$Y_{i t-3}$ & 0.088 & $(0.001)$ & 0.066 & $(0.000)$ & 0.074 & $(0.000)$ & 0.060 & $(0.000)$ \\
\hline$Y_{i t-4}$ & 0.051 & $(0.128)$ & 0.016 & $(0.250)$ & 0.055 & $(0.000)$ & 0.037 & $(0.001)$ \\
\hline Age & -0.0005 & $(0.607)$ & -0.015 & $(0.518)$ & 0.001 & $(0.445)$ & -0.033 & $(0.085)$ \\
\hline Age squared & -0.00005 & $(0.959)$ & 0.014 & $(0.494)$ & -0.001 & $(0.086)$ & 0.005 & $(0.757)$ \\
\hline Married/Co-habiting & 0.004 & $(0.127)$ & -0.137 & $(0.078)$ & 0.003 & $(0.204)$ & -0.121 & $(0.021)$ \\
\hline Household Size & 0.002 & $(0.126)$ & -0.016 & $(0.567)$ & -0.0002 & $(0.833)$ & 0.014 & $(0.485)$ \\
\hline Number of Children & 0.0002 & $(0.911)$ & 0.031 & $(0.532)$ & -0.0004 & $(0.843)$ & 0.158 & $(0.000)$ \\
\hline Unemployed & -0.00008 & $(0.981)$ & -0.189 & $(0.022)$ & -0.002 & $(0.531)$ & -0.032 & $(0.629)$ \\
\hline Self Employed & -0.003 & $(0.389)$ & 0.001 & $(0.986)$ & -0.004 & $(0.387)$ & 0.162 & $(0.077)$ \\
\hline Retired & -0.003 & $(0.499)$ & -0.078 & $(0.481)$ & -0.0008 & $(0.788)$ & -0.032 & $(0.629)$ \\
\hline Employment other & -0.009 & $(0.055)$ & -0.161 & $(0.100)$ & 0.001 & $(0.647)$ & -0.068 & $(0.107)$ \\
\hline Long-term sick & -0.002 & $(0.739)$ & 0.094 & $(0.482)$ & 0.005 & $(0.340)$ & -0.050 & $(0.537)$ \\
\hline Household Income & 0.005 & $(0.001)$ & 0.028 & $(0.337)$ & 0.002 & $(0.146)$ & -0.002 & $(0.915)$ \\
\hline Accidents & 0.003 & $(0.027)$ & -0.023 & $(0.537)$ & 0.004 & $(0.035)$ & 0.040 & $(0.218)$ \\
\hline Degree/Higher degree & 0.0002 & $(0.984)$ & -0.328 & $(0.297)$ & 0.011 & $(0.518)$ & -0.913 & $(0.006)$ \\
\hline HND/A-Level & -0.00007 & $(0.994)$ & -0.091 & $(0.711)$ & 0.010 & $(0.507)$ & -0.707 & $(0.016)$ \\
\hline O-Level/ CSE & -0.002 & $(0.846)$ & -0.070 & $(0.778)$ & 0.009 & $(0.516)$ & -0.650 & $(0.014)$ \\
\hline Non-White & -0.006 & $(0.177)$ & -0.042 & $(0.727)$ & -0.003 & $(0.660)$ & -0.325 & $(0.011)$ \\
\hline South West & 0.005 & $(0.093)$ & -0.022 & $(0.772)$ & 0.002 & $(0.406)$ & -0.014 & $(0.825)$ \\
\hline London & 0.002 & $(0.414)$ & 0.067 & $(0.362)$ & 0.0004 & $(0.904)$ & 0.082 & $(0.276)$ \\
\hline Midlands & 0.0005 & $(0.823)$ & -0.031 & $(0.630)$ & -0.005 & $(0.117)$ & 0.0003 & $(0.996)$ \\
\hline Yorkshire & -0.002 & $(0.432)$ & -0.033 & $(0.610)$ & -0.006 & $(0.091)$ & 0.073 & $(0.238)$ \\
\hline North West & -0.0005 & $(0.817)$ & -0.003 & $(0.956)$ & -0.003 & $(0.238)$ & 0.162 & $(0.014)$ \\
\hline North East & -0.004 & $(0.196)$ & 0.048 & $(0.549)$ & -0.011 & $(0.005)$ & 0.168 & $(0.017)$ \\
\hline Scotland & -0.002 & $(0.406)$ & 0.217 & $(0.000)$ & -0.007 & $(0.009)$ & 0.242 & $(0.000)$ \\
\hline Wales & -0.001 & $(0.589)$ & 0.179 & $(0.003)$ & -0.011 & $(0.004)$ & 0.146 & $(0.017)$ \\
\hline Northern Ireland & -0.003 & $(0.614)$ & 0.236 & $(0.018)$ & -0.006 & $(0.342)$ & 0.051 & $(0.630)$ \\
\hline
\end{tabular}

Table 5: Fourth-order single equation estimates. Coefficient estimates and p-values in parentheses. $Y_{i t-1}, \ldots, Y_{i t-4}=H_{i t-1}, \ldots, H_{i t-4}$ for the health equation and $S_{i t-1}, \ldots, S_{i t-4}$ for the smoking equation. All regressions include year dummies. 


\section{References}

Adams, P., Hurd, M.D., McFadden, D., Merrill, A., Ribeiro, T. (2003). Healthy, wealthy, and wise? Tests for direct causal paths between health and socioeconomic status. Journal of Econometrics, 112: 3-56.

Adda, J., Lechene, V. (2013). Health selection and the effect of smoking on mortality. The Scandinavian Journal of Economics, 115(3): 902-931.

Adda, J., Cornaglia, F. (2006). Taxes, cigarette consumption, and smoking intensity. The American Economic Review, 96(4): 1013-1028.

Adda, J., Cornaglia, F. (2010). The effect of bans and taxes on passive smoking. American Economic Journal: Applied Economics, 2(1): 1-32.

Arcidiacono, P. (2007) Living Rationally Under the Volcano? An Empirical Analysis of Heavy Drinking and Smoking. International Economic Review, 48(1): 37-65.

Arellano, M., Bond, S. (1991). Some tests of specification for panel data: Monte Carlo evidence and an application to employment equations, The Review of Economic Studies 58(2): 277-297.

Balia, S., Jones, A.M. (2008). Mortality, lifestyle and socio-economic status. Journal of Health Economics, 27(1): 1-26.

Baltagi, B. H. (2007). On the use of panel data methods to estimate rational addiction models. Scottish Journal of Political Economy, 54(1): 1-18.

Baltagi, B. H. and Geishecker, I. (2006). Rational alcohol addiction: evidence from the Russian Longitudinal Monitoring Survey. Health Economics, 15(9): 893-914.

Baltagi, B. H. and Griffin, J. M. (2001). The econometrics of rational addiction: the case of cigarettes. Journal of Business and Economic Statistics, 19(4): 449-454.

Baltagi, B. H. and Griffin, J. M. (2002). Rational addiction to alcohol: panel data analysis of liquor consumption. Health Economics, 11(6): 485-491.

Baltagi, B. H. and Levin, D. (1986). Estimating dynamic demand for cigarettes using panel data: the effects of bootlegging, taxation and advertising reconsidered. The Review of Economics and Statistics, 68(1): 148-155.

Becker, G.S. (1965). A Theory of the Allocation of Time. Economic Journal, 75(299): 493-517. 
Becker, G.S., Woytinsky, W.S. (1993). Human capital and the personal distribution of income: An analytical approach. 1967. Institute of Public Administration, University of Michigan, Ann Arbor. Also available in: G.S. Becker. Human Capital (3rd edition). University of Chicago Press. 102-158.

Becker, G. S., Grossman, M. and Murphy, K. M. (1994). An Empirical Analysis of Cigarette Addiction. American Economic Review, 84(3): 396-418.

Becker, G. S. and Murphy, K. M. (1988). A Theory of Rational Addiction. The Journal of Political Economy, 96(4): 675-700.

Blundell, R., Bond, S. (1998). Initial conditions and moment restrictions in dynamic panel-data models. Journal of Econometrics, 87(1): 115-143.

Blundell, R., Bond, S., Windmeijer, F. (2001). Estimation in dynamic paneldata models: Improving the performance of the standard GMM estimator. In Nonstationary Panels, Cointegrating Panels and Dynamic Panels, Advances in Econometrics, Volumn 15, ed. Baltagi, B., Fomby, T.B., Carter Hill, R. 53-92. New York, Elsevier.

Brazier J., Roberts J., Deverill, M. (2002). The estimation of a preferencebased measure of health from the SF-36. Journal of Health Economics, 21(2): 271-292.

Chaloupka, F. (1991). Rational Addictive Behavior and Cigarette Smoking. Journal of Political Economy, 99(4): 722-742.

Christelis, D., Sanz-de-Galdeano, A. (2009). Smoking persistence across countries: an analysis using semi-parametric dynamic panel data models with sensitivity. Discussion Paper No. 4336, Institute for the Study of Labour (IZA), July 2009.

Contoyannis, P., Jones, A.M., Rice, N. (2004). The dynamics of health in the British Household Panel Survey. Journal of Applied Econometrics, 19: 473-503.

Darden, M. (2012). Smoking, Expectations, and Health: A Dynamic Stochastic Model of Lifetime Smoking Behavior. Working Papers, Department of Economics, Tulane University. Available to download at: http://ideas.repec.org/p/tul/wpaper/1204.html

Doll, R., Peto, R., Boreham, J., Sutherland, I. (2004). Mortality in relation to smoking: 50 years' observations on male British doctors. British Medical Journal; doi:10.1136/bmj.38142.554479.AE

Ehrlich, I. and Chuma, H. (1990). A model of the demand for longevity and the value of life extension. Journal of Political Economy, 98(4): 761-782. 
Ferguson, B., Lim, G.C. (2003). Dynamic Economic Models in Discrete Time: Theory and empirical applications. New York, Routledge.

Forster, M., (2001). The meaning of death: some simulations of a model of healthy and unhealthy consumption. Journal of Health Economics, 20(4); 613-638.

Frijters, P., Haisken-DeNew, J.P., Shields, M.A. (2005). The causal effect of incoem on health: Evidence from the German reunification. The Journal of Health Economics, 24(5): 997-1017.

Galama, T.S., van Kippersluis, H (2015). A theory of education and health. CESR-Schaeffer working Paper No 2015-001.

Gilleskie, D. (1998). A dynamic stochastic model of medical care use and work absence. Econometrica, 66(1): 1-45.

Goldberg D, Williams P. (1988). A Users Guide to the General Health Questionnaire. Windsor: NFER-Nelson.

Grossman, M. (1972). On the Concept of Health Capital and the Demand for Health. Journal of Political Economy, 80(2): 223-255.

Grossman, M. (1993). The economic analysis of addictive behavior. In Economics and the Prevention of Alcohol-Related Problems, Hilton, M.E. Bloss, G. (eds), NIAAA Research Monograph No. 25, NIH Pub. No. 933513. Bethesda, MD: National Institute on Alcohol Abuse and Alcoholism: 91123.

Grossman, M. (2000) Chapter 7: The human capital model, In Handbook of Health Economics, Volumn 1 Culyer, A.J., Newhouse, J.P. (eds); Elsevier, North Holland.

Grossman, M. and Chaloupka, F. J. (1998). The demand for cocaine by young adults: a rational addiction approach. Journal of Health Economics, 17(4); 427-474.

Grossman, M., Chaloupka, F. J. and Sirtalan, I. (1998). An empirical analysis of alcohol addiction: Results from the monitoring the future panels. Economic Inquiry, 36(1): 39-48.

Gruber, J., Koszegi, B. (2001). Is addiction rational? Theory and evidence. Quarterly Journal of Economics, 116(4): 1261-1303.

Hai, R., Heckman, J. (2014). A dynamic model of health, education and wealth with creedit constraints and rational addiction. Download from: http://www.bus.miami.edu/_assets/files/faculty-and-research/conferencesand-seminars/economics-seminars/falls-2014/papers_Hai.pdf. 
Hausman, J., Taylor, W. (1981). Panel data and unobserved individual effects. Econometrica, 49(6): 1377-1398.

Jones, A. M. and Labeaga, J. M. (2003). Individual heterogeneity and censoring in panel data estimates of tobacco expenditure. Journal of Applied Econometrics, 18(2): 157-177.

Keeler, T. E., Hu, T.-W., Barnett, P. G. and Manning, W. G. (1993). Taxation, regulation, and addiction: A demand function for cigarettes based on timeseries evidence. Journal of Health Economics, 12(1): 1-18.

Labeaga, J. M. (1999). A Double-Hurdle Rational Addiction Model with Heterogeneity: Estimating the Demand for Tobacco. Journal of Econometrics, 93(1): 49-72.

Leonard, D., Long, N.V. (1992). Optimal Control Theory and Static Optimization in Economics, Chapter 10, Section 10.1 "Problems with two-state variables": pp307-310. Cambridge University Press.

Lindström, M. (2010). Social capital, economics conditions, marital status and daily smoking: A population-based study. Pulic Health, 124(2): 71-77.

Lynn P. (ed.) (2006). Quality Profile: British Household Panel Survey Version 2.0: Waves 1 to 13: 1991-2003. Colchester, Institute for Social and Economic Research, University of Essex.

Meer, J,. Miller, D., Rosen, H. (2003). Exploring the health-wealth nexus. Journal of Health Economics, 22: 713-730.

Mellward, D., Karlson, S. (2011). Tobacco use among minority ethnic populations and cessation interventions. A Race Equality Foundation Briefing Paper, London.

Mincer, J. (1974). Schooling, Experience and Earnings. Columbia University Press for the National Bureau of Economic Research, New York.

Nickell, S. (1981). Biases in dynamic models with fixed effects. Econometrica, 49(6): 1417-1426.

Pitchford, J.D. (1977). Two state variable problems. In Applications of Control Theory to Economic Analysis, Pictchford, J.D., Turnovsky, S.J. (eds), North-Holland, Amsterdam: 127154

Saffer, H. and Chaloupka, F. (1999). The demand for illicit drugs. Economic Inquiry, 37(3): 401-411.

Wagstaff, A. (1986). The demands for health: Some new empirical evidence. Journal of Health Economics, 5: 195-233. 
Ware, J.E., Snow, K.K., Kolinski, M., Gandeck, B. (1993). SF-36 Health survey manual and interpretation guide. The Health Institute, New England Medical Centre, Boston, MA.

Waters, T. M. and Sloan, F. A. (1995). Why do people drink? Tests of the rational addiction model. Applied Economics, 27(8); 727-736.

Windmeijer, F. (2005). A finite sample correction for the variance of linear efficient two-step GMM estimators. Journal of Econometrics, 126: 25-52.

Zweifel, P. (2012). The Grossman model after 40 years. The European Journal of Health Economics, 13(6); 677-682. 


\section{Appendix A}

Consider the system of two second-order difference equations (??) for $Y_{1}$ and $Y_{2}$ as follows:

$$
\begin{aligned}
& Y_{1 t}=\phi_{10}+\phi_{11} Y_{1 t-1}+\phi_{12} Y_{2 t-1}+\theta_{11} X_{1 t}+\theta_{12} X_{2 t}+\varepsilon_{1 t} \\
& Y_{2 t}=\phi_{20}+\phi_{21} Y_{1 t-1}+\phi_{22} Y_{2 t-1}+\theta_{21} X_{1 t}+\theta_{22} X_{2 t}+\varepsilon_{2 t}
\end{aligned}
$$

Abstracting from the constant terms without loss of generality, the above can be written in matrix form as,

$$
\left[\begin{array}{l}
Y_{1 t} \\
Y_{2 t}
\end{array}\right]=\left[\begin{array}{ll}
\phi_{11} & \phi_{12} \\
\phi_{21} & \phi_{22}
\end{array}\right]\left[\begin{array}{l}
L Y_{1 t} \\
L Y_{2 t}
\end{array}\right]+\left[\begin{array}{ll}
\theta_{11} & \theta_{12} \\
\theta_{21} & \theta_{22}
\end{array}\right]\left[\begin{array}{l}
X_{1 t} \\
X_{2 t}
\end{array}\right]+\left[\begin{array}{l}
\epsilon_{1 t} \\
\epsilon_{2 t}
\end{array}\right]
$$

where $L$ is the lag operator. Since $L$ is multiplicative, equation (??) can be expressed as,

$$
\left[\begin{array}{c}
Y_{1 t} \\
Y_{2 t}
\end{array}\right]=\left[\begin{array}{cc}
L \phi_{11} & L \phi_{12} \\
L \phi_{21} & L \phi_{22}
\end{array}\right]\left[\begin{array}{l}
Y_{1 t} \\
Y_{2 t}
\end{array}\right]+\left[\begin{array}{ll}
\theta_{11} & \theta_{12} \\
\theta_{21} & \theta_{22}
\end{array}\right]\left[\begin{array}{l}
X_{1 t} \\
X_{2 t}
\end{array}\right]+\left[\begin{array}{l}
\epsilon_{1 t} \\
\epsilon_{2 t}
\end{array}\right]
$$

Combining the vectors for $Y_{t}$ gives,

$$
\left[\begin{array}{cc}
1-L \phi_{11} & -L \phi_{12} \\
-L \phi_{21} & 1-L \phi_{22}
\end{array}\right]\left[\begin{array}{l}
Y_{1 t} \\
Y_{2 t}
\end{array}\right]=\left[\begin{array}{ll}
\theta_{11} & \theta_{12} \\
\theta_{21} & \theta_{22}
\end{array}\right]\left[\begin{array}{l}
X_{1 t} \\
X_{2 t}
\end{array}\right]+\left[\begin{array}{l}
\epsilon_{1 t} \\
\epsilon_{2 t}
\end{array}\right]
$$

This can be rearranged such that,

$$
\left[\begin{array}{c}
Y_{1 t} \\
Y_{2 t}
\end{array}\right]=\left[\begin{array}{cc}
1-L \phi_{11} & -L \phi_{12} \\
-L \phi_{21} & 1-L \phi_{22}
\end{array}\right]^{-1}\left[\begin{array}{ll}
\theta_{11} & \theta_{12} \\
\theta_{21} & \theta_{22}
\end{array}\right]\left[\begin{array}{l}
X_{1 t} \\
X_{2 t}
\end{array}\right]+\left[\begin{array}{cc}
1-L \phi_{11} & -L \phi_{12} \\
-L \phi_{21} & 1-L \phi_{22}
\end{array}\right]^{-1}\left[\begin{array}{c}
\epsilon_{1 t} \\
\epsilon_{2 t}
\end{array}\right]
$$

The inverse matrix which appears twice on the RHS of equation (??) can be written:

$$
\left[\begin{array}{cc}
1-L \phi_{11} & -L \phi_{12} \\
-L \phi_{21} & 1-L \phi_{22}
\end{array}\right]^{-1}=\frac{1}{\operatorname{Det} A}\left[\begin{array}{cc}
1-L \phi_{22} & L \phi_{12} \\
L \phi_{21} & 1-L \phi_{11}
\end{array}\right]
$$


where $\operatorname{Det} A$ is the determinant of the matrix being inverted:

$\operatorname{Det} A=\left[1-L \phi_{11}\right]\left[1-L \phi_{22}\right]-L^{2} \phi_{12} \phi_{21}=1-\left[\phi_{11}+\phi_{22}\right] L+\left[\phi_{11} \phi_{22}-\phi_{12} \phi_{21}\right] L^{2}$

Using equation (??) allows us to write,

$\operatorname{Det} A\left[\begin{array}{l}Y_{1 t} \\ Y_{2 t}\end{array}\right]=\left[\begin{array}{cc}1-L \phi_{22} & L \phi_{12} \\ L \phi_{21} & 1-L \phi_{11}\end{array}\right]\left[\begin{array}{cc}\theta_{11} & \theta_{12} \\ \theta_{21} & \theta_{22}\end{array}\right]\left[\begin{array}{c}X_{1 t} \\ X_{2 t}\end{array}\right]+\left[\begin{array}{cc}1-L \phi_{22} & L \phi_{12} \\ L \phi_{21} & 1-L \phi_{11}\end{array}\right]\left[\begin{array}{c}\epsilon_{1 t} \\ \epsilon_{2 t}\end{array}\right]$

recalling that $\operatorname{Det} A$ is a scalar - the determinant of the matrix to be inverted.

Multiplying out the first two matrices on the RHS, such that

$$
\left[\begin{array}{cc}
1-L \phi_{22} & L \phi_{12} \\
L \phi_{21} & 1-L \phi_{11}
\end{array}\right]\left[\begin{array}{cc}
\theta_{11} & \theta_{12} \\
\theta_{21} & \theta_{22}
\end{array}\right]=\left[\begin{array}{cc}
{\left[1-L \phi_{22}\right] \theta_{11}+L \phi_{12} \theta_{21}} & {\left[1-L \phi_{22}\right] \theta_{12}+L \phi_{12} \theta_{22}} \\
\theta_{11} L \phi_{21}+\left[1-L \phi_{11}\right] \theta_{21} & L \phi_{21} \theta_{12}+\left[1-L \phi_{11}\right] \theta_{22}
\end{array}\right]
$$

Substituting equation (??) into equation (??) gives,

$$
\begin{array}{r}
\operatorname{Det} A\left[\begin{array}{l}
Y_{1 t} \\
Y_{2 t}
\end{array}\right]=\left[\begin{array}{ll}
{\left[1-L \phi_{22}\right] \theta_{11}+L \phi_{12} \theta_{21}} & {\left[1-L \phi_{22}\right] \theta_{12}+L \phi_{12} \theta_{22}} \\
\theta_{11} L \phi_{21}+\left[1-L \phi_{11}\right] \theta_{21} & L \phi_{21} \theta_{12}+\left[1-L \phi_{11}\right] \theta_{22}
\end{array}\right]\left[\begin{array}{c}
X_{1 t} \\
X_{2 t}
\end{array}\right] \\
+\left[\begin{array}{cc}
1-L \phi_{22} & L \phi_{12} \\
L \phi_{21} & 1-L \phi_{11}
\end{array}\right]\left[\begin{array}{c}
\epsilon_{1 t} \\
\epsilon_{2 t}
\end{array}\right]
\end{array}
$$

Now take the top row of equation (??), which is the expression for $Y_{1 t}$ 
where we are assuming that $Y_{1}$ is the observable variable. That will be

$$
\begin{array}{r}
\operatorname{Det} A Y_{1 t}=\theta_{11} X_{1 t}+\left[\phi_{12} \theta_{21}-\phi_{22} \theta_{11}\right] L X_{1 t}+\theta_{12} \\
X_{2 t}+\left[\phi_{12} \theta_{22}-\phi_{22} \theta_{12}\right] L X_{2 t} \\
+\left[\epsilon_{1 t}-\phi_{22} L \epsilon_{1 t}+\phi_{12} L \epsilon_{2 t}\right]
\end{array}
$$

Substituting for $\operatorname{Det} A$ from equation (??),

$$
\begin{array}{r}
{\left[1-\left[\phi_{11}+\phi_{22}\right] L+\left[\phi_{11} \phi_{22}-\phi_{12} \phi_{21}\right] L^{2}\right] Y_{1 t}=\phi_{11} X_{1 t}+\left[\phi_{12} \theta_{21}-\phi_{22} \theta_{11}\right] L X_{1 t}} \\
+\theta_{12} X_{2 t}+\left[\phi_{12} \theta_{22}-\phi_{22} \theta_{12}\right] L X_{2 t}+\left[\epsilon_{1 t}-\phi_{22} L \epsilon_{1 t}+\phi_{12} L \epsilon_{2 t}\right]
\end{array}
$$

Applying the Lag operator gives,

$$
\begin{array}{r}
Y_{1 t}-\left[\phi_{11}+\phi_{22}\right] Y_{1 t-1}+\left[\phi_{11} \phi_{22}-\phi_{12} \phi_{21}\right] Y_{1 t-2}=\phi_{11} X_{1 t}+\left[\phi_{12} \theta_{21}-\phi_{22} \theta_{11}\right] X_{1 t-1} \\
+\theta_{12} X_{2 t}+\left[\phi_{12} \theta_{22}-\phi_{22} \theta_{12}\right] X_{2 t-1}+\left[\epsilon_{1 t}-\phi_{22} \epsilon_{1 t-1}+\phi_{12} \epsilon_{2 t-1}\right]
\end{array}
$$

Isolating $Y_{1 t}$ on the left hand side gives,

$$
\begin{array}{r}
Y_{1 t}=\left[\phi_{11}+\phi_{22}\right] Y_{1 t-1}-\left[\phi_{11} \phi_{22}-\phi_{12} \phi_{21}\right] Y_{1 t-2}+\phi_{11} X_{1 t}+\left[\phi_{12} \theta_{21}-\phi_{22} \theta_{11}\right] X_{1 t-1} \\
+\theta_{12} X_{2 t}+\left[\phi_{12} \theta_{22}-\phi_{22} \theta_{12}\right] X_{2 t-1}+\left[\epsilon_{1 t}-\phi_{22} \epsilon_{1 t-1}+\phi_{12} \epsilon_{2 t-1}\right]
\end{array}
$$

The purpose of the transformation using the lag operators is to leave us with, on the RHS, lagged values of the observable $Y$, values of the exogenous variables, and a disturbance term which involves (in the 2 equation case) both $\epsilon_{1}$ and $\epsilon_{2}$ values and, by its involvement of both current and lagged $\epsilon$ 's, requiring us to use an estimating method which allows for a serially correlated residual term.

The structure in equation (??) also has the appeal that we can see how 
the roots of the system are derived from the coefficients on the two lags of $Y_{1}$ and, by comparing it with the original matrix form, we can see that the roots of equation (??) will be the same as the roots of the original system of two FODEs, justifying our argument that the dynamics of the system are retained by the transformation. 


\section{Appendix B}

Instrument set for single fourth-order equation in first-differenced form

$$
\left(\begin{array}{ccccccccccccc}
S_{i 1} & 0 & 0 & \ldots & \ldots & 0 & \ldots & \ldots & 0 & \Delta X_{i 6} & \Delta X_{i 5} & \Delta X_{i 4} & \Delta X_{i 3} \\
0 & S_{i 1} & S_{i 2} & \ldots & \ldots & 0 & \ldots & \ldots & 0 & \Delta X_{i 7} & \Delta X_{i 6} & \Delta X_{i 5} & \Delta X_{i 4} \\
\vdots & \vdots & \vdots & \ddots & & \vdots & \ddots & & \vdots & \vdots & \vdots & \vdots & \vdots \\
\vdots & \vdots & \vdots & & \ddots & \vdots & & \ddots & \vdots & \vdots & \vdots & \vdots & \vdots \\
0 & 0 & 0 & \ldots & \ldots & S_{i 1} & \ldots & \ldots & S_{i T-5} & \Delta X_{i T} & \Delta X_{i T-1} & \Delta X_{i T-2} & \Delta X_{i T-3}
\end{array}\right)
$$

